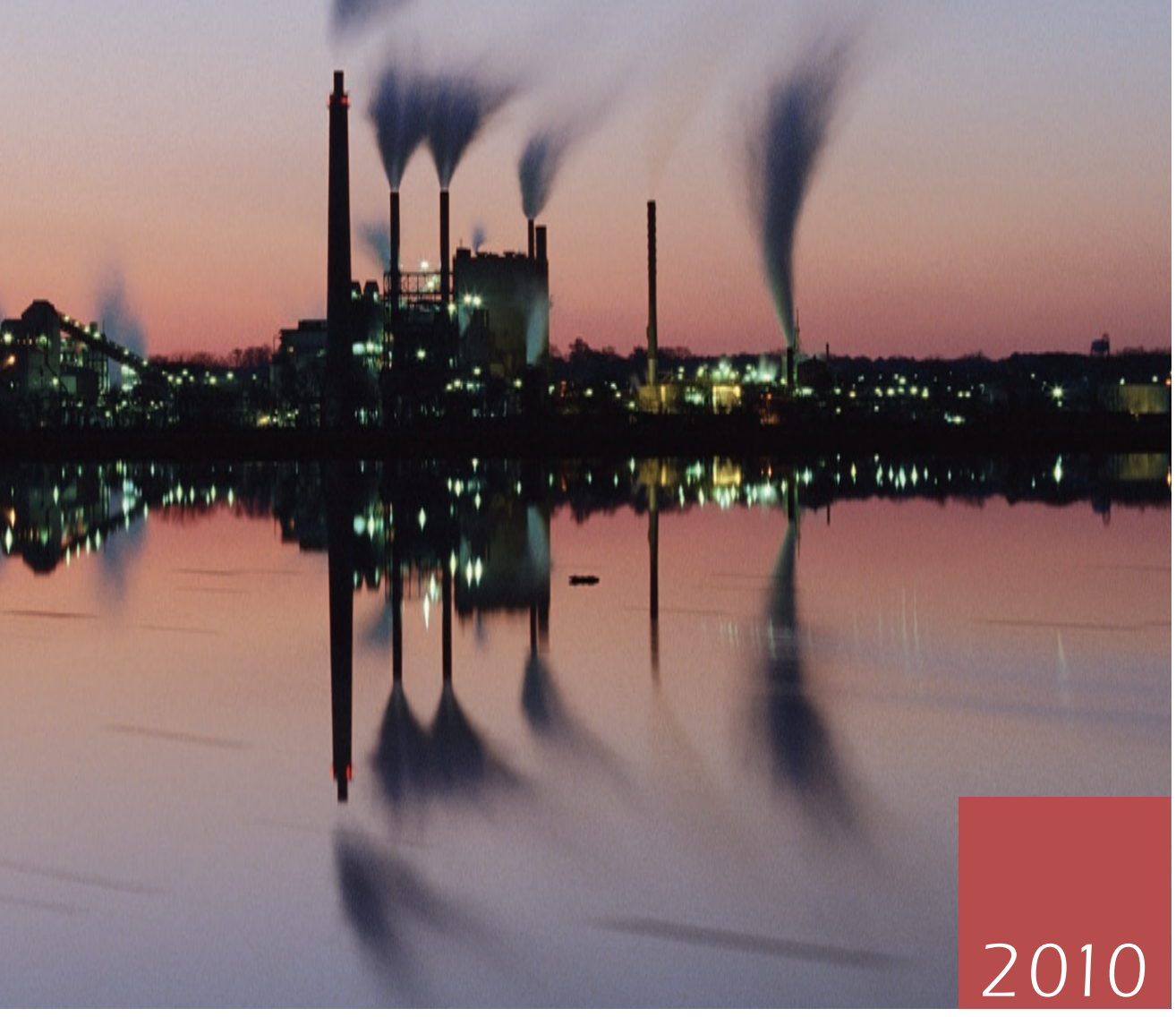

\title{
India's Downstream Petroleum Sector
}

\section{Refined product pricing and refinery investment}

International Energy Agency

Kieran Clarke

(Australian Department of

Resources, Energy and Tourism) and Dagmar Graczyk (IEA)

\section{WORKING PAPER}


The International Energy Agency (IEA), an autonomous agency, was established in November 1974. Its mandate is two-fold: to promote energy security amongst its member countries through collective response to physical disruptions in oil supply and to advise member countries on sound energy policy.

The IEA carries out a comprehensive programme of energy co-operation among 28 advanced economies, each of which is obliged to hold oil stocks equivalent to 90 days of its net imports. The Agency aims to:

- Secure member countries' access to reliable and ample supplies of all forms of energy; in particular, through maintaining effective emergency response capabilities in case of oil supply disruptions.

- Promote sustainable energy policies that spur economic growth and environmental protection in a global context - particularly in terms of reducing greenhouse-gas emissions that contribute to climate change.

- Improve transparency of international markets through collection and analysis of energy data.

- Support global collaboration on energy technology to secure future energy supplies and mitigate their environmental impact, including through improved energy

efficiency and development and deployment of low-carbon technologies.

Find solutions to global energy challenges through engagement and dialogue with non-member countries, industry, international organisations and other stakeholders.

IEA member countries:

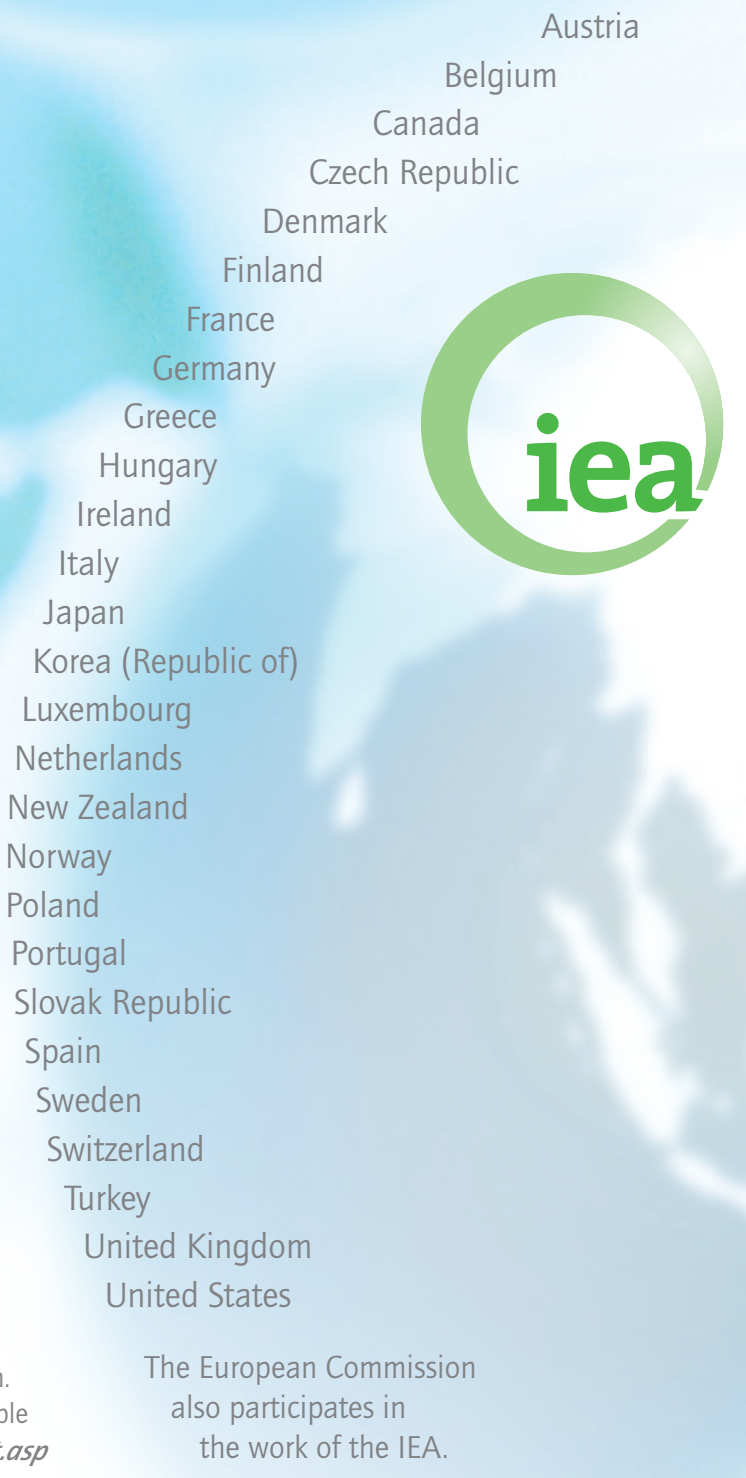

\section{(c) OECD/IEA, 2010 \\ International Energy Agency \\ 9 rue de la Fédération \\ 75739 Paris Cedex 15, France}

Please note that this publication is subject to specific restrictions that limit its use and distribution. The terms and conditions are available online at www.iea.org/about/copyright.asp
International Energy Agency

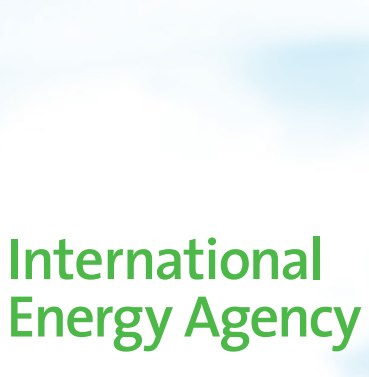




\section{India's Downstream Petroleum Sector}

\section{Refined product pricing and refinery investment}

The views expressed in this Working Paper are those of the author(s) and do not necessarily reflect the views or policy of the International Energy Agency or of its individual member countries. As this paper is a Work in Progress, designed to elicit comments and further debate, comments are welcome, directed to the authors at india@iea.org
International Energy Agency

Kieran Clarke

(Australian Department of Resources, Energy and TOURISM) and Dagmar Graczyk (IEA) 



\section{Table of Contents}

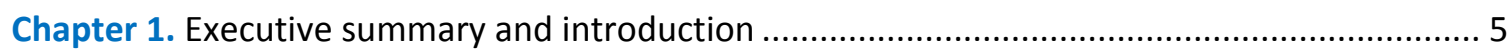

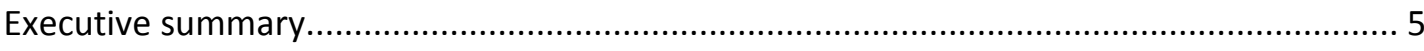

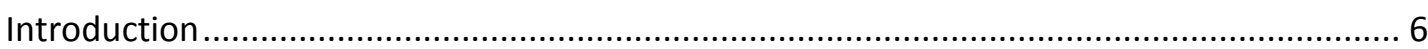

Chapter 2. Petroleum pricing and "effective subsidies" in India .............................................. 9

Petroleum product pricing since the end of the Administered Pricing Mechanism ............... 9

The cost of "effective" subsidies: under-recoveries to Oil Marketing Companies ................ 10

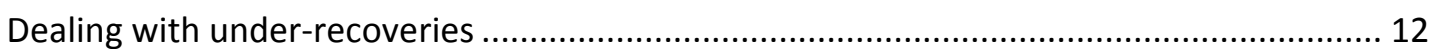

Contribution to fiscal and macroeconomic instability ..................................................... 14

The impact of pricing arrangements on downstream development .................................... 16

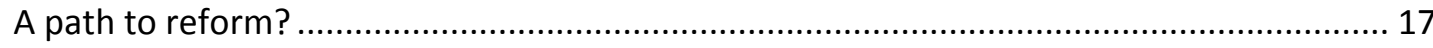

Chapter 3. The downstream petroleum sector: policy goals and regulatory environment ......... 19

Key policy goals in Indian petroleum refining and retail ...................................................... 19

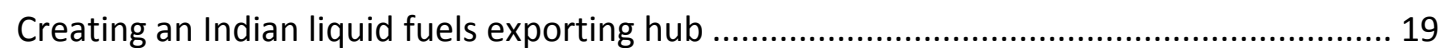

An institutional framework for policy achievement and sectoral growth? .......................... 20

Assessing India's downstream sector regulatory framework ............................................. 24

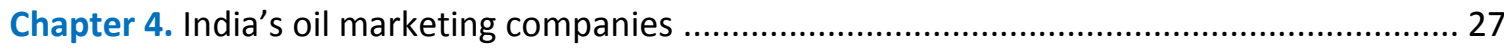

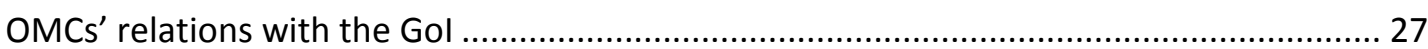

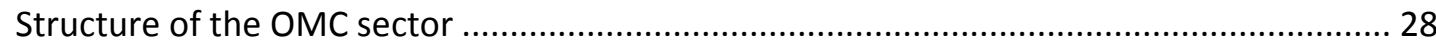

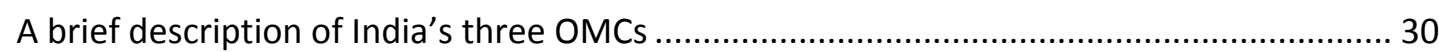

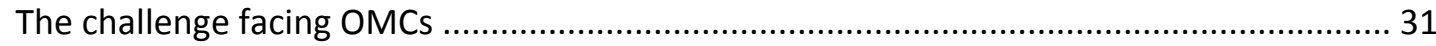

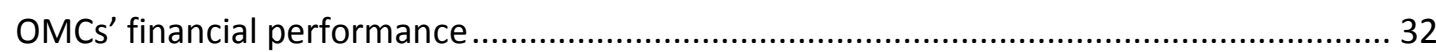

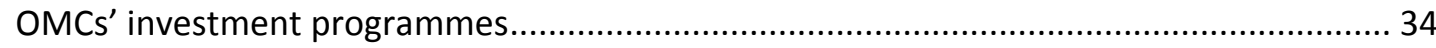

Assessing OMCs: do OMCs provide for growth in India's downstream sector? .................... 36

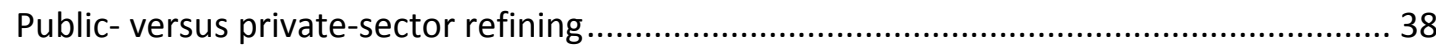

Chapter 5. Will India emerge as a major global refined product exporting hub? ......................... 39

Demand growth in Asia-Pacific and the Middle East .......................................................... 40

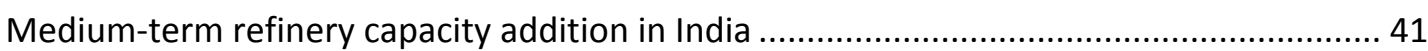

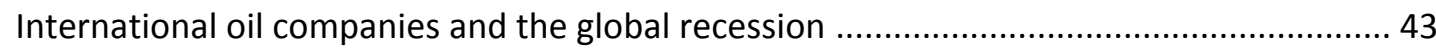

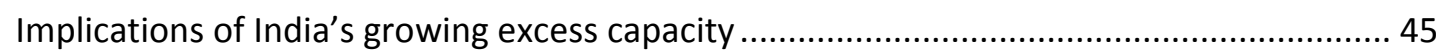

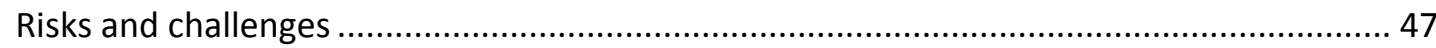

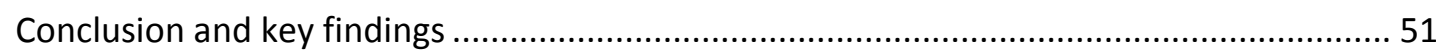


Chapter 6. A return to the issue of product pricing: paths toward market reform...................... 53

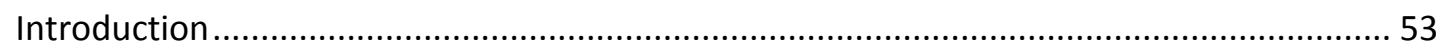

Making markets work: the secondary benefits of reform................................................ 54

The possible roads to reform (or the road less travelled) .................................................. 55

Page | $4 \quad$ Establishing workable price ceilings in Indian product markets ........................................ 57

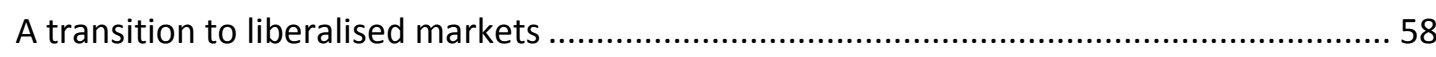

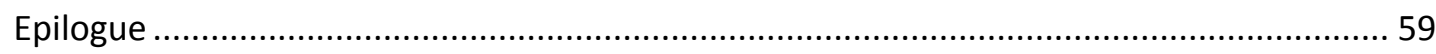

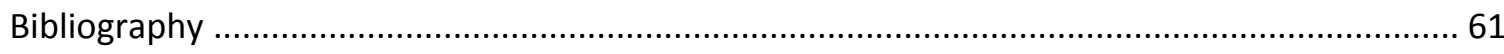

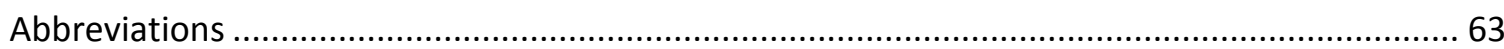

\section{List of charts}

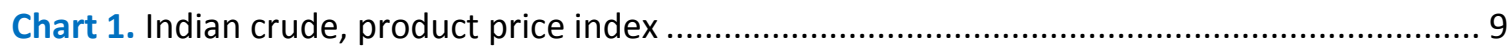

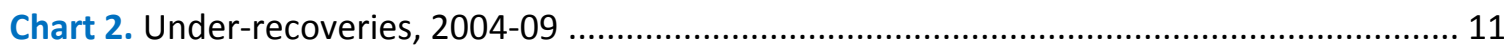

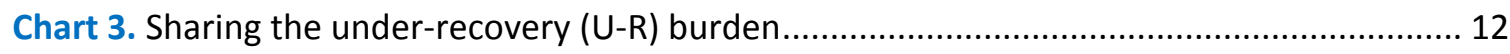

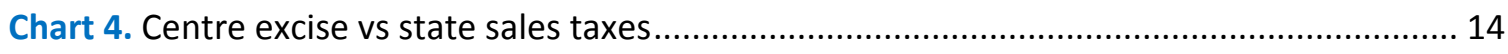

Chart 5. Comparing magnitudes: oil sector taxes, under-recoveries and oil bonds..................... 15

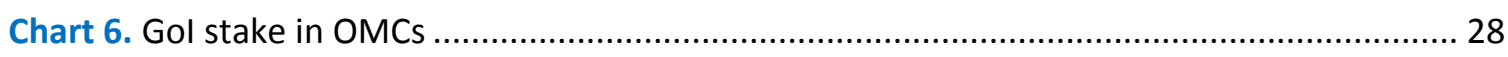

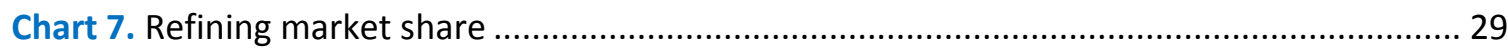

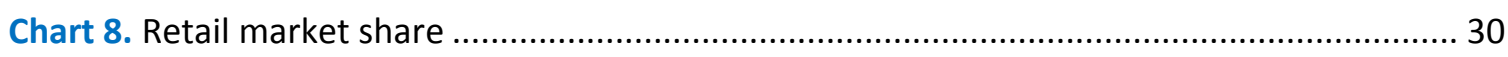

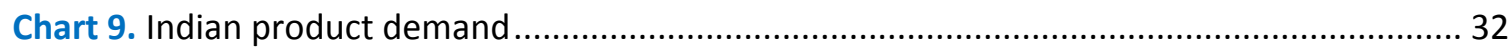

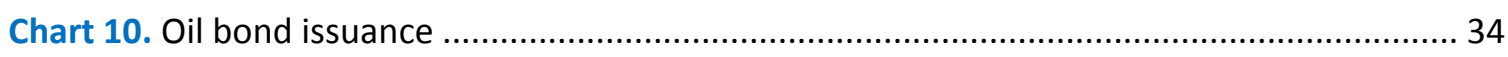

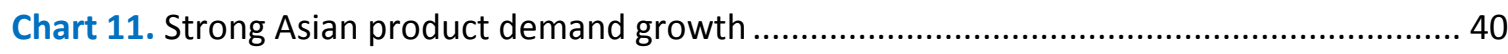

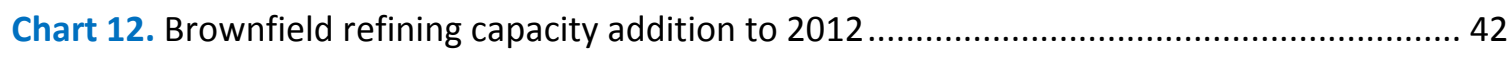

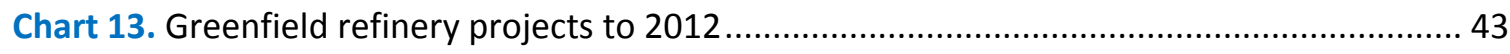

Chart 14. Indian refining capacity vs domestic demand, 2009-12 ............................................. 46

Chart 15. Forecast Asia-Pacific refined product exports, 2012 .................................................. 47

Chart 16. Indian refining capacity vs domestic demand, 2012-15........................................... 50

\section{List of tables}

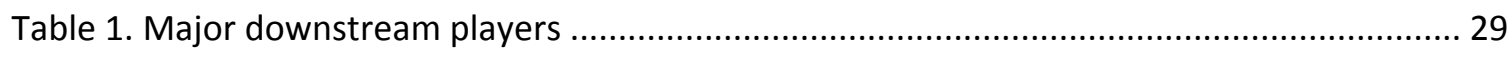

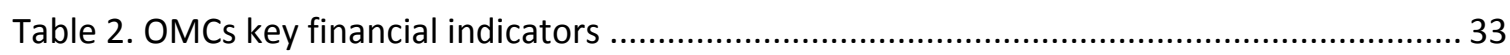




\section{Chapter 1. Executive summary and introduction ${ }^{1}$}

\section{Executive summary}

- India maintains price controls on four "sensitive" petroleum products - petrol, diesel, liquefied petroleum gas (LPG), and kerosene - to insulate consumers against high global crude oil prices. India's government-owned Oil Marketing Companies (OMCs) are tasked by the Government of India (Gol) to sell these products in retail markets at a centrallydetermined realised sales price. Upward revisions to prices in response to higher global crude prices are rare.

- As international crude prices began structural appreciation from 2004, OMCs began recording significant "under-recoveries" on the sale of sensitive petroleum products. Underrecoveries are a notional measure representing the difference between the trade-parity refinery-gate cost of refined product paid by OMCs and their managed sale price. In FY 2008-09, OMCs under-recoveries amounted to over USD 25 billion.

- The Gol has been forced to issue hundreds of billions of Indian rupees to OMCs to counteract mass under-recoveries since 2005 in order to maintain the solvency of these key companies. This has increasingly occurred via the extension of off-budget "oil bonds" - debt securities issued to OMCs to be traded by these companies for liquid cash, or to be used as collateral for borrowing in financial markets. The Gol issued close to USD 20 billion in oil bond debt to OMCs in FY 2008-09.

- The fiscal impact of under-recoveries resulting from managed product prices has become acute. Off-budget debt issuance, in particular oil bond issuance, has led to a fiscal overflow in India. India's government deficit (across levels of government and including off-budget components) more than doubled in nominal terms from 5.7\% of GDP in FY 2007-08 to $11.4 \%$ in FY 2008-09. This has greatly reduced the flexibility of the Gol in responding to the current global recession, threatened to compromise the Gol's ability to borrow costeffectively in international capital markets and sparked fears of "twin deficits" stagnation.

- Two key objectives motivate the Gol's policy in India's downstream petroleum sector: (a) ensuring India's growing refined product demand is met at affordable prices over time; and (b) establishing India as a major global refined product exporter. Aside from its fiscal implications, India's current petroleum product pricing regime has implications for the achievement of these goals, and for the emergence of timely refining investments that are crucial to their achievement.

- To begin with, current pricing practices have made public-sector OMCs reliant on the Gol for working capital from period-to-period. Despite this, this paper finds that OMCs have invested strongly in refinery capacity in recent years. Between 2007 and 2012 - the years of India's $11^{\text {th }}$ Five Year Plan - OMCs will have added over 600000 barrels per day (bbl/d) in greenfield refining capacity and close to $300000 \mathrm{bbl} / \mathrm{d}$ in brownfield capacity. This will more than match India's rapidly growing refined product demand in this period. The OMC sector is therefore defined by heavy-handed regulation and lacklustre commercial performance, yet robust investment, capacity addition and growth.

\footnotetext{
${ }^{1}$ In all that follows, US dollar conversions are based on the average dollar-rupee exchange rate for fiscal
} 
- Private-sector refinery investment in India, too, is shown to be robust in both the recent past and in the near future. From the commissioning of Reliance Industry Limited's (RIL) ${ }^{2}$ Jamnagar II refinery in late 2008 to the scheduled commissioning of Essar Oil's Vadinar II refinery in 2012, private-sector refiners will have added around 1.2 million barrels per day $(\mathrm{mb} / \mathrm{d})$ of new refining capacity. This has been driven by: (a) private-sector refiners' scope

Page $\mid 6$ to profitably supply domestic Indian markets by selling wholesale to OMCs, thus avoiding exposure to managed prices; and (b) India's significant comparative advantages as a base for export-oriented refining operations.

- As a combined result of public-sector and private-sector refinery investments in the recent past, India will emerge by 2012 as Asia's largest refined product exporter, surpassing Singapore. India will remain one of Asia's two largest refined product exporters for the foreseeable future. India's sudden emergence as a global petroleum producing hub is likely to have far-reaching implications for regional product markets, increasing the depth of product flows and strengthening supply chains, especially for high-end industrial product and clean transport fuels. The establishment of India's large-scale export-oriented refining sector marks the acceleration of a fundamental shift in the configuration of global refining in which mature economies increasingly look to production hubs in Asia and the Middle East to supply incremental refined product demand.

- While the Gol's downstream policies are likely to achieve their ambitious objectives in the medium term, they have done so at a tremendous fiscal cost. There is an urgent need to reduce the fiscal burden of the Gol's system of unofficial petroleum product subsidies; to increasingly base OMC investment on market drivers and retained earnings rather than government dictat; and to foster petroleum product conservation and substitution through clear price signals in product markets. The Gol must therefore increasingly move towards market-based petroleum pricing reform, while at the same time protecting access to energy markets for more vulnerable Indian consumers. Initially, this will require a concerted combination of regulated pricing reform and targeted subsidies.

\section{Introduction}

\section{Background and structure to the study}

This study provides a holistic examination of pricing and investment dynamics in India's downstream petroleum sector. It begins in Chapter 2 with an analysis of current petroleum product pricing practices in India, which involve price controls on India's four most-consumed products - petrol, diesel, LPG and kerosene. ${ }^{3}$ Chapter 2 above all highlights the tremendous fiscal cost of current pricing arrangements. However, the examination of petroleum pricing in Chapter 2 (in combination with Chapter 3, which examines the policy and regulatory structures governing India's downstream sector) also provides the analytical framework by which sectoral

\footnotetext{
${ }^{2}$ Reliance Industry Limited (abbreviated to RIL), run by Mukesh Ambani, is one sister company constituting the Reliance conglomerate as a whole. The conglomerate was split after irreconcilable differences emerged between Mukesh Ambani and brother Anil, who once jointly ran the conglomerate. RIL is the branch of the original Reliance conglomerate involved in the downstream petroleum sector.

${ }^{3}$ These products make up over $60 \%$ of Indian petroleum product consumption. LPG and kerosene are the key cooking fuels, outside of biomass, for India's poor population, making them particularly sensitive, in a developmental sense.
} 
dynamics of investment and growth are considered and understood throughout the rest of the study.

A comprehensive consideration of sectoral investment dynamics is undertaken in Chapters 4 and 5. These chapters particularly emphasise an examination of: (a) the ability of key downstream companies to meet rapidly growing Indian product demand; and, most importantly, (b) the prospective emergence of India as major global refined product exporter, an outcome with considerable potential implications for the evolution of global and regional product markets. Refinery investment, of course, is key in both these instances. Chapters 4 and 5 therefore concentrate on investment in refining capacity by both public- and private-sector corporations.

The study ends with an examination of product market pricing policy in Chapter 6. As will be argued, petroleum pricing policy is entirely unsustainable in its current form. Chapter 6 therefore returns to the issue of pricing originally examined in Chapter 2, and looks at potential paths towards market-based reform along which the Gol may move, while at the same time protecting energy market access for India's large poor population.

\section{Setting the context of the study}

Why examine pricing and refining investment in India's downstream petroleum sector?

1. India as a globally significant oil consumer: In 2009, India was the world's fourth largest consumer of crude oil and petroleum products after the United States, China and Japan, with product consumption growing by a remarkable $5.2 \%$ per annum in 2009 , despite the effects of the global recession. ${ }^{4}$ India is forecast to become the world's third largest oil consumer by 2014, although per capita consumption rates are expected to remain well below OECD averages. ${ }^{5}$ Given the growing significance of India as a crude consumer, it is important to understand and analyse the pricing, regulatory and investment dynamics at play in its downstream petroleum sector. These factors will to a large extent shape domestic supply and consumption patterns currently and into the future, which in turn will also largely determine the nature of India's involvement in global energy markets, especially refined product and crude markets.

2. The impact of oil-sector expenditures on budgetary stability: As mentioned above, in FY 2008-09, "under-recoveries" accruing to India's publicly-owned OMCs exceeded USD 25 billion. In order to uphold the solvency of OMCs, the Gol has increasingly issued oil bonds to OMCs. In March 2009, ratings agency Standard \& Poor's threatened to downgrade India's sovereign credit rating to "junk" status due to the ballooning of the Central Budget deficit, largely as a result of the government's large-scale "off-budget" debt issuance. Current downstream sector policy in India, therefore, has contributed tangibly to increased fragility and instability in India's government finances. The issue of petroleum product pricing therefore has significant implications for the health of India's national budget and for India's macroeconomic stability as a whole. With India emerging as the world's fourth largest economy (in purchasing power parity terms), macroeconomic instability of this kind is of global concern.

\footnotetext{
${ }^{4}$ International Energy Agency (2010), Oil Market Report, 11 February 2010.

${ }^{5}$ International Energy Agency (2009), Tables: Reviewing Medium Term Horizon - December 2009, http://www.oilmarketreport.org/indexsubscribers.asp
} 
3. Investment in India's downstream sector: Investment in India's downstream sector will determine the ability of the domestic downstream industry to meet strongly growing Indian refined product demand. If capacity addition lags demand growth Indian downstream firms will be required to draw on global refined product markets to meet product demand, compromising India's energy security, putting pressure on under-established regional

Page 18 refined product supply chains (and prices), and markedly increasing India's energy import costs.

More significantly from a global perspective, the nature of downstream investment in India over time will determine the success of the Gol's ambitious policy to establish a worldcompetitive refined product export industry in India, based on the Singaporean model - a process started in earnest already by RIL (and to a lesser extent Essar's) world-leading refinery expansions in Gujarat State. The rapid emergence of India as one of the world's largest refined product exporters has the potential to revolutionise regional product markets, especially in what will be termed the "Indian Ocean rim"; increase the energy security of import-dependent nations; and fundamentally shift the configuration of regional refining and product supply-chains. 


\section{Chapter 2. Petroleum pricing and "effective subsidies" in India}

\section{Petroleum product pricing since the end of the Administered Pricing Mechanism}

In April 2002 India abolished the Administrative Pricing Mechanism (APM) controlling the price of petroleum products. Under the APM, product prices were directly administered by the Gol, based on an opaque and complex "cost of operating capital plus" formula.

Chart 1. Indian crude, product price index

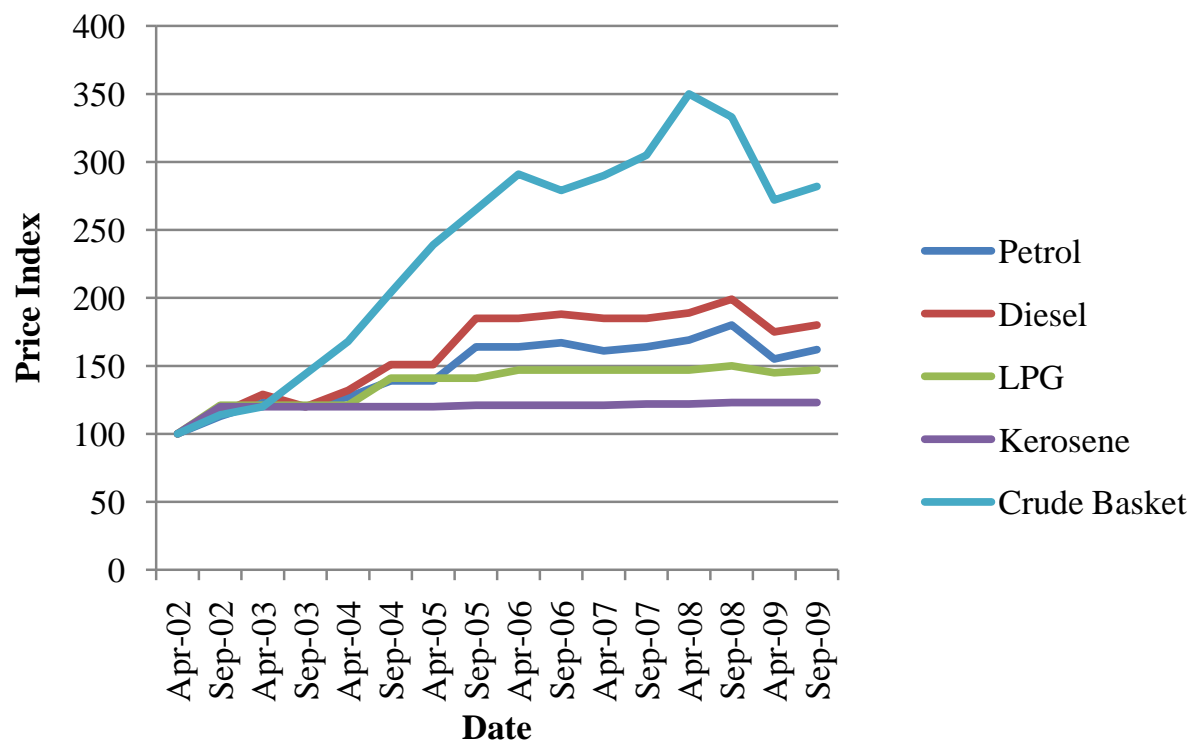

Source: PPAC data, http://ppac.org.in/

Under the new regime, OMCs would be free to set retail product prices based on an import parity pricing formula. The domestic refining and retail sector was also opened to private-sector firms, leading to the emergence of a small private-sector retailing presence in India consisting of firms such as RIL. Because of the importance of LPG and kerosene as cooking fuels for India's low-income population, per unit subsidies funded from the government's budget were maintained on LPG and on a fixed proportion of supplied kerosene. However, these were to be phased out between 2005 and 2007. Subsidies are yet to be phased out. Under the new pricing regime, it was expected that retail prices for petroleum products (including prices for domestic kerosene and LPG) would fluctuate with changes in the price of India's crude basket. As depicted in Chart 1, however, this has not been the case. ${ }^{6}$ While global crude prices have appreciated considerably since 2002, retail prices for "sensitive fuels" - petrol, diesel, LPG and

\footnotetext{
${ }^{6}$ All data in the charts included in Chapter 1 are sourced from India's Petroleum Planning and Analysis Cell (PPAC). See: http://ppac.org.in/.
} 
kerosene - have risen very slowly, and in the case of LPG and kerosene, have hardly increased at all. $^{7}$

In practice, the post-APM product pricing regime beginning in 2002 was adhered to only very briefly by the Gol in these four key markets. With the sustained rise in crude prices beginning in 2004, the Gol increasingly looked to restrict the ability of OMCs to increase retail prices of these

Page | 10 four products, so as to protect Indian consumers. By mid-2004, the post-APM model of product pricing had been effectively abandoned, with the Gol once again centrally controlling upward price revisions. Since 2004, retail prices for petrol and diesel have been revised upward less than ten times by the Gol, while LPG and kerosene prices have remained effectively fixed. ${ }^{8}$

\section{The cost of "effective" subsidies: under-recoveries to Oil Marketing Companies}

The effect of significantly lower product retail prices than crude input prices - a large "effective subsidy" - has been the increasing accumulation of "under-recoveries" by OMCs. Underrecoveries are a notional measure representing the difference between the trade-parity cost of refined product paid by OMCs and their realised sale price. ${ }^{9}$ In fact, the actual refinery-gate prices paid by OMCs are not necessarily congruent with formula-based trade-parity prices as formally calculated. Trade-parity prices depend on a variety of factors such as contract prices and transport costs, meaning under-recoveries cannot be isolated on the balance sheets of OMCs. ${ }^{10}$ They are an indicative measure of the rate of effective subsidisation.

There has been significant debate within India over the appropriateness of "under-recoveries" as a category for measuring the burden of the current pricing policy on OMCs. It is argued that the refinery-gate prices paid by OMCs (all of whom are vertically-integrated refiners) are less than trade-parity prices, as currently calculated, meaning the actual effect of managed prices is less than that suggested by under-recovery figures. However, this debate is not of great significance here. The key fact is that Indian domestic product prices have not risen in line with the significant generalised increase in international crude prices that has occurred since 2004-05, and as such have placed a significant subsidy burden on OMCs. Under-recoveries as a

\footnotetext{
${ }^{7}$ The prices of petrol and diesel are protected because of the importance of these products as transport fuels (especially as they are widely used in public transport, food freight, etc). Diesel in particular is important, as it makes up over one-third of India's petroleum product consumption, and has uses outside transport, e.g., as an input into agricultural production.

${ }^{8}$ By implication, the private-sector retail operations that had been rapidly set up in the aftermath of the dismantling of the APM were gradually made uneconomical with a return of de facto administered pricing. As a result, RIL, Essar, and Shell (the three private-sector firms with licences to retail in India) were forced to close their retail outlets across India.

${ }^{9}$ Trade-parity pricing has replaced import-parity pricing as a benchmark for pricing calculations since the 2006 recommendations of the Rangajaran Committee, as India is both an importer and exporter of refined product. Under-recoveries on LPG and kerosene are calculated over and above the (relatively insignificant) on-budget rate of subsidisation. On-budget allocated subsidies for LPG and kerosene are USD 568 million in FY 2009-10, a significant number, however much less than total under-recoveries (i.e., the total effective subsidy).

${ }^{10}$ In the same way, it is important to note that under-recoveries and balance-sheet losses are not congruent. Losses are a balance-sheet measure which takes into account alternative income streams such as dividend income, pipeline income, inventory changes, profit from freely priced product and refinery margins in the case of integrated companies.
} 
category provide a notional indication of the extent of this burden. Just as importantly, the measure continues to be used by the Gol to inform policy decisions.

Chart 2. Under-recoveries, 2004-09

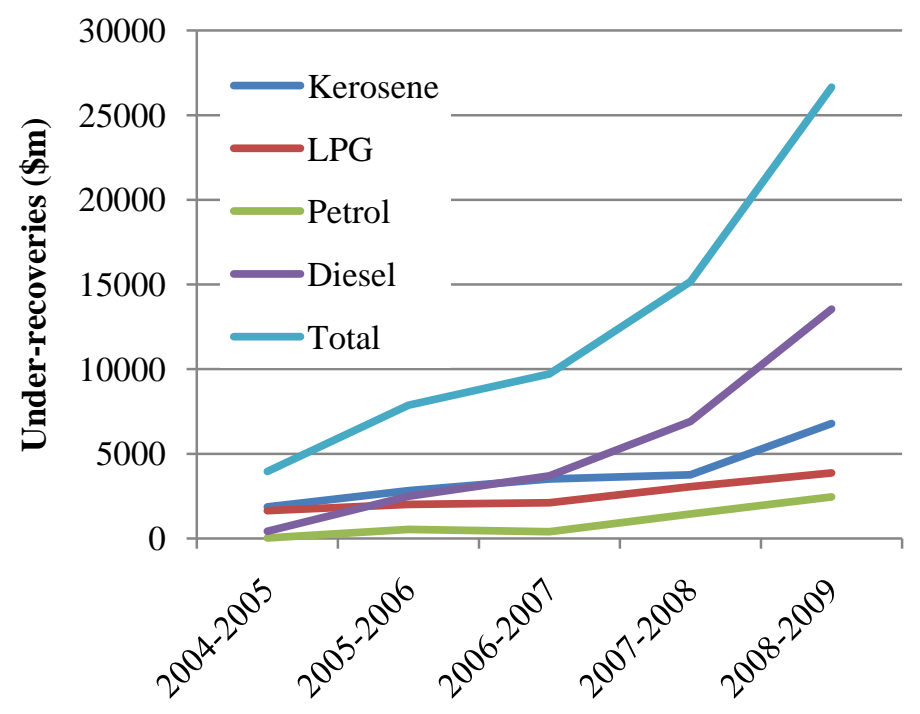

Source: PPAC.

As Chart 2 shows, under-recoveries have escalated sharply in recent years, from less than USD 10 billion in FY 2004-05 to close to USD 30 billion in FY 2008-09. Indeed, the generalised moderation in crude prices since mid-2008 has not implied a wholesale reduction in the incidence of under-recoveries. In FY 2008-09, the Indian crude basket price averaged just over USD $80 / \mathrm{bbl}$. At current retail prices, under-recoveries will be incurred from any crude price above around USD 55-60/bbl.

The mounting burden of under-recoveries has seriously affected the operational functioning and financial health of OMCs. For example, between April and December 2008 alone, India's three key OMCs lost between 25 and $43 \%$ of their total net worth. ${ }^{11}$ Already in 2005 , it was recognised by the Gol that OMCs could not function properly and sustainably under the weight of building under-recoveries, shrinking liquidity and significantly impaired corporate flexibility. Instead of burdening the balance sheets of OMCs with massive under-recovery losses, therefore, the Gol has increasingly looked for alternative solutions to the under-recovery issue. Along with requiring upstream oil and gas PSUs (Public-Sector Undertakings) to provide OMCs discounted crude and other tariffs (see "Upstream share" in Chart 3) the Gol has increasingly looked to issue off-budget "oil bonds" to OMCs to paper over the systemic financial and commercial issues reproduced within the current product pricing regime. Chart 3 shows the incidence of final under-recovery burden-sharing over time, after the Gol's oil bond remuneration to OMCs has taken place. ${ }^{12}$ The proportion of the under-recovery burden absorbed by the issuance of oil bonds has risen rapidly, while in FY 2008-09, financially weakened OMCs did not absorb any under-recoveries from their balance sheets.

\footnotetext{
${ }^{11}$ Total net worth, or "book value", refers to the total assets minus total liabilities of a corporation.

${ }^{12}$ Note, while OMCs were exempt from absorbing a share of the under-recovery burden, public upstream companies were not, due to the fact that high oil prices have contributed to "windfall" profits for these firms.
} 
Chart 3. Sharing the under-recovery (U-R) burden

Page | 12

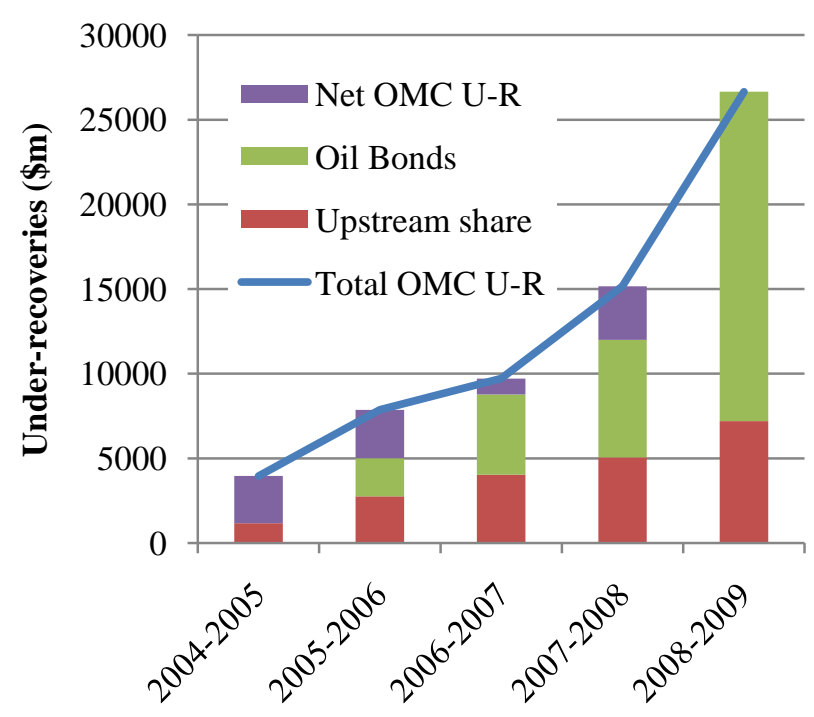

Source: PPAC.

\section{Dealing with under-recoveries}

\section{Oil bonds}

Oil bond issuance has become the key fiscal tool for "solving" the petroleum pricing issue. In 2008-09, the Gol issued just under USD 20 billion in oil bonds to OMCs. The oil bonds issued by the Gol typically have maturities of ranging between 5-7 years, although maturities can be up to 20 years. Oil bonds vary in their status of tradability. The first oil bonds issued by the government will begin to reach maturity from 2010, from which time their fiscal burden will begin to be felt. Tradable bonds are typically sold on bond markets immediately by OMCs to generate liquidity. Non-tradable bonds can otherwise be used by OMCs as collateral to raise cash, although both OMCs and Indian banks have shown a strong preference for tradability.

Indian oil bonds have not been given Statutory Liquidity Ratio (SLR) status by the Reserve Bank of India (RBI). This means they cannot be counted as verifiable liquid assets in the reserves of Indian banks to make up requisite commercial SLRs, which has implications for the tradability of oil bonds on secondary bond markets.

Aside from the significant fiscal consequences for the Gol implied by the mass issuance oil bonds (which will be examined below), this process has also not proved to be the commercial panacea for OMCs' financial problems, as hoped. Despite a general climate of falling interest rates in 2009 and increasingly risk averse financial practices - conditions which, ceteris paribus, should support the face value of existing sovereign debt - OMCs have had great difficulty liquidating oil bonds for the full value of the coupon as issued. There are two key reasons for this:

- Saturated bond markets: Several years of massive oil, farm and fertiliser bond issuance by the Gol have created a significant bond market glut in India. OMCs have therefore had to compete in buyers' bond markets to sell their fixed-yield assets, leading to falling bond prices. 
- $\quad$ Non-SLR status: As mentioned, the RBI precludes oil bonds from SLR status. ${ }^{13}$ This non-SLR status has meant that, in the context of bond market over-supply, Indian banks and financial institutions have shown little enthusiasm for large-scale acquisition of fixed-yield oil bonds as they have been issued, forcing OMCs to discount bond values.

Indian policy makers have begun to take ad hoc steps to reform the current conditions under which OMCs liquidate oil bonds in open markets. In particular, the Gol has sought to agree arrangements with the RBI under which the RBI would absorb excess oil bond supply. In particular, with OMCs struggling to generate the foreign exchange (forex) liquidity necessary to purchase imported inputs, especially crude, the government has asked the RBI to make bondfor-forex swaps at prevailing market rates. As the situation stands, however, the losses made by OMCs on bond values only serve to heighten the fiscal impact of India's current petroleum pricing regime. As bond values fall and OMCs ability to use these assets to absorb the impact of under-recoveries lessens, the Gol is inevitably forced into yet further rounds of debt issuance.

\section{Rationalisation of taxes and duties}

In order to lessen the under-recovery burden on OMCs, the Gol has looked to rationalise the complex system of taxes and duties on petroleum products, in tandem with large-scale bond issuance. Clearly, given a centrally administered retail price for petroleum products, a reduction in the proportion of realised prices that are made up by tax will reduce the under-recovery accruing to OMCs. ${ }^{14}$

For example, between the end of 2004 and June 2008, the Gol brought excise tax on petrol down from a rate of $26 \%$ ad valorem plus INR 7.50 per litre to a flat rate of INR 13.35 per litre. Excise on diesel was reduced by a similar magnitude. Excise on LPG and kerosene was reduced from $8 \%$ and $16 \%$ respectively in 2004 to nil by mid-2008. Between 2004 and June 2008 , the Gol also reduced the customs duty on imported petrol and diesel from $20 \%$ ad valorem to $2.5 \%$. This is further to abolishing custom duties on LPG and kerosene in early-2005. Customs duty on imported crude was reduced to nil in June 2008.

Across levels of Indian government, however, the rationalisation of petroleum product taxes and duties has been considerably unbalanced and uneven. While the Gol has shown a willingness to cut into revenues to help deal with petroleum pricing issues, state governments have been mostly unwilling to undermine this reliable, inelastic source of revenues. While states have almost uniformly moved from an ad valorem sales taxation structure to a flat-rate structure (in order to reduce pressure on prices in times of rapidly increasingly crude costs), they have aimed to ensure that total revenue has not been undermined. Thus, as Chart 4 shows, since 2005-06, the Gol's excise revenues have plateaued and even declined marginally as excise tax rates have fallen, while total sales tax revenues accruing to states have shown strong growth.

\footnotetext{
${ }^{13}$ Some Indian commentators have suggested that the RBI has deliberately persisted with the exclusion of oil bonds from SLR status to protect the demand for the Gol's borrowings, given current macroeconomic uncertainty and bond market glut.

${ }^{14}$ As reported in an IEA paper (http://www.iea.org/papers/2009/petroleum pricing.pdf), the tax collected on petroleum products significantly outweighs the subsidies on these products, and represents a significant source of revenue for both central and state Governments. The rate of taxation has kept Indian retail prices relatively comparable (although still lower for all key products) to neighbouring countries such as Pakistan and Bangladesh.
} 
Chart 4. Centre excise vs state sales taxes

Page | 14

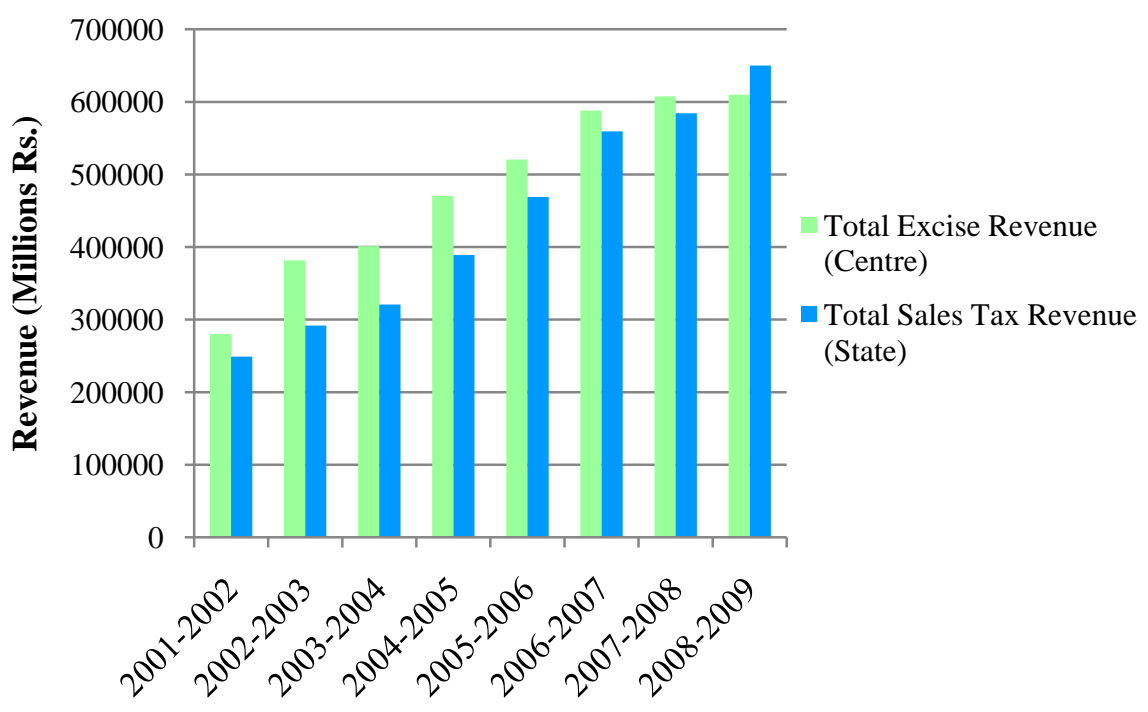

Source: PPAC.

There is thus an emerging issue of "vertical fiscal imbalance" within India's system of petroleum market regulation. On the one hand, the Gol is systematically cutting taxation revenues while rapidly increasing outlays (in the form of oil bonds) to deal with inherent petroleum pricing issues. On the other hand, state governments continue to reap tax revenues from the petroleum sector while offering no financial support for the crippling system of effective subsidies.

Clearly, under-recoveries suffered by OMCs would have been larger in the last several years had the Gol not sought to reduce taxes and levies on petroleum products. Nevertheless, simply cutting taxation rates cannot solve the underlying issue of absent cost-reflectivity in product markets. By cutting taxes the Gol therefore risks undermining a crucial source of revenue, which may be spent in support of basic developmental programmes, while providing only a very partial and incomplete solution to the petroleum pricing issue. In fact, by cutting taxes it undermines its ability to fund the rapidly increasing outlays required to support the subsidies regime, an idea explored below. Lastly, reducing taxes now will make it very difficult for future governments to raise taxation rates on petroleum products in the future, depriving policy makers of a key demand-side management and environmental policy tool.

\section{Contribution to fiscal and macroeconomic instability}

Large-scale under-recoveries accruing to OMCs and massive oil bond issuance are highly destabilising to the Indian central government finances and for India's macroeconomic health in general. As Chart 5 shows, in 2008-09, under-recoveries are rapidly encroaching on total tax collected (by state and central governments) from the oil and petroleum sector for the first time ${ }^{15}$ This is not surprising. While under-recoveries have risen at a worrying pace, the Gol has

\footnotetext{
${ }^{15}$ This includes taxes accruing on the whole range of petroleum products, not just the four "sensitive" products. It also includes taxes accruing at all levels of government.
} 
forcefully cut petroleum product taxation. With rising expenditure obligations and falling revenues, the net ability of the petroleum sector itself to fund current pricing arrangements is therefore rapidly being eroded, thus forcing the Gol to consolidate spending in other areas of its budget, or rather, as it has shown itself willing to do, to issue significant quantities of off-budget debt.

Chart 5. Comparing magnitudes: oil sector taxes, under-recoveries and oil bonds

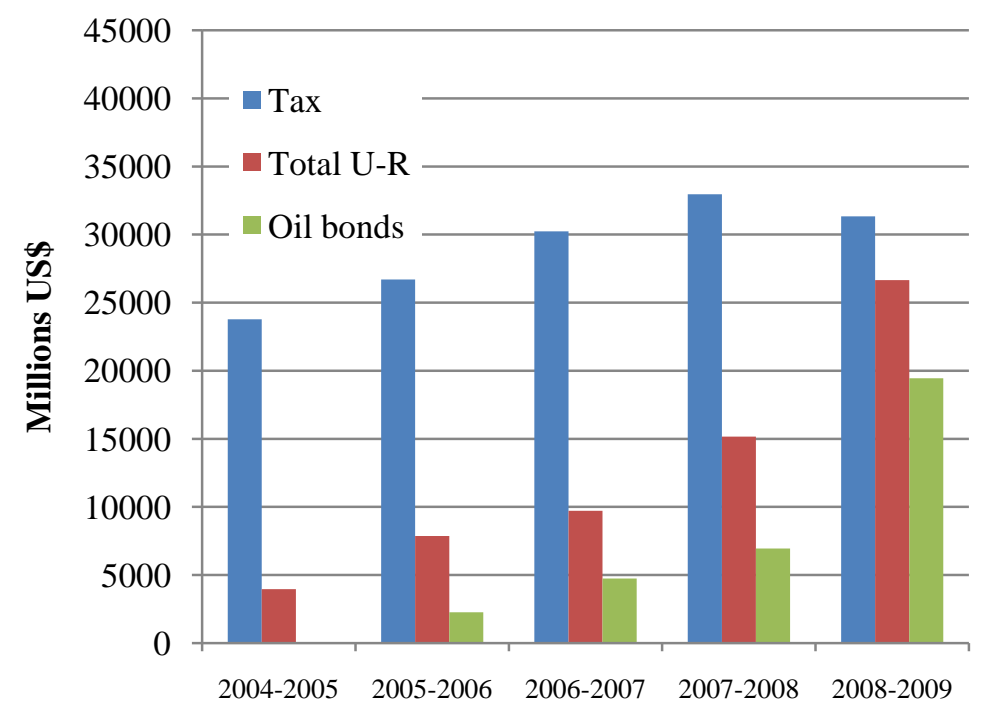

Source: PPAC.

The moderation of international crude prices since late-2008 has eased this situation (without removing it). In early 2009, private-sector retailers even began re-opening previously closed retail outlets across India, although the rebound in crude prices from mid-2009 largely ended this process. Further, in contrast to official intransigence to sanction upward price revisions under conditions of rising prices, the Gol showed itself to be willing to quickly and appreciably revise down product prices in an environment of falling global crude prices (as seen clearly in late-2008 and early-2009). When this occurs, OMCs are not significantly better-off as a result of crude price moderation.

Mounting oil bond debt has led to a period of considerable budgetary excess in India. With tax revenues falling, stimulus spending accelerating, and off-budget debt issuance increasing rapidly, India's government deficit (across all levels of government and including off-budget components) more-than-doubled in nominal terms from 5.7\% of GDP in FY 2007-08 to $11.4 \%$ in FY 2008-09. Total state and central government debt is estimated at $82 \%$ of GDP. As rating agency Standard \& Poor's (S\&P) is keen to highlight, the key factor in this fiscal excess is the rapid increase in off-budget debt issuance, and in particular oil bond issuance. ${ }^{16}$

According to S\&P, "India's fiscal deficit is entirely unsustainable in the medium-term". ${ }^{17}$ It has warned that without tangible signs of fiscal tightening, it will downgrade India's sovereign credit from BBB (its lowest investment grade) to "junk" status. A downgrade of India's sovereign credit

\footnotetext{
${ }^{16}$ So-called "fertilizer bonds" - similar to oil bonds but issued to farmers to offset the increasing cost of fertilizer and other petrochemical feedstocks - amounted to close to USD 10 billion in FY 2008-09.

${ }^{17}$ Standard \&Poor's (2009), “India Sovereign Credit Rating: Press Release”, February.
} 
rating will only worsen the effect of large-scale oil bond issuance on the health of government finances. As a result of several years of accumulated off-budget debt issuance, interest payments on government debt already consume around $24 \%$ of general government revenue. Sovereign "junk" status will force investors to demand higher interest rates on Indian government paper, both for oil bonds, other off-budget debt issuance and general government Page | 16 borrowings - which itself will increase the proportion of the Gol's revenues devoted simply to interest payments on debt. Further, if, as expected, oil bonds are given greater SLR status, general government borrowings will have to compete with these securities for buyers - again putting upward pressure on government paper interest rates.

This situation of serious budgetary instability is currently combined with cyclical weakness in the Indian economy. After averaging over 7\% GDP growth between 2003 and 2007, India's growth fell to $6.6 \%$ in FY $2008-09 .^{18}$ With Indian exports hit hard by falling demand in key markets, India's current account deficit widened appreciably to $3.7 \%$ of GDP in 2008-09. The emergence of "twin deficits" in India, especially of a large fiscal deficit, has caused countless commentators to compare India's current situation with that experienced in the lead-up to the "Gulf War" balance-of-payments crisis in 1991. In fact, India's current economic positioning is quite different to that experienced in the late-1980s, not least in the relative resilience of its external position. Under current economic conditions, however, recent fiscal profligacy is likely to limit the Gol's options regarding further direct economic stimulus, as well as to put significant downward pressure on the rupee. India's position is therefore in contrast to the fiscal situation of China, which, despite considerable stimulus spending in 2009, is robust enough to provide scope for stimulus into the future if necessary, and to avoid the need for strict fiscal austerity in the aftermath of the global recession.

\section{The impact of pricing arrangements on downstream development}

Current policies within India's downstream petroleum sector clearly have implications for investment decisions within this sector, which in turn will determine the way the sector evolves in the medium-term. Under the current system, OMCs are largely dependent on indirect handouts from the Gol for working capital. The repeated extension of this is the result of a range of uncertain political processes.

The extent to which this affects the willingness and ability of OMCs to invest in additional capacity and technology or to conduct productive long-term planning will be examined in Chapter 4. Will current investment effectively allow for sectoral growth and meet rapidly expanding Indian petroleum demand? And what role does the current system of pricing play in informing investment decisions? Chapter 5 will look at the downstream investment plans of private-sector refiners, in the context of what is presented in this chapter, to examine the potential for India to emerge as a global refining centre and liquid fuels trading hub. The following chapter will lay the foundation for these analyses of sectoral investment dynamics by outlining the policy and regulatory frameworks governing India's downstream sector.

\footnotetext{
${ }^{18}$ Source: The Hindu (2009), "India clocks 6.6 percent growth in 2008-2009", 30 May. GDP figures for 2008-09 do not reflect India's growth trend from 2003 because they were affected by the financial crisis late in the second half of the calendar year. Neither however do they reflect the full impact of the global recession on the Indian economy, as growth remained strong for the first half of 2008.
} 


\section{A path to reform?}

There has been considerable talk of reform to petroleum product pricing arrangements since the re-election of the Congress-led government in May 2009. For a significant period before elections were held, the government deferred making major reform decisions that might incite the electorate. However, Prime Minister Singh and his Cabinet had reiterated their commitment to reducing government controls on fuel pricing in late-2008 as part of a review of the Integrated Energy Policy of 2006 (IEP).

A proposal for pricing reform emanating from the Ministry of Petroleum and Natural Gas (MPNG) was circulated immediately following the 2009 election. The proposal suggested that OMCs set product prices every three months, based on the quarterly average price of the Indian crude basket. This, it was proposed, would occur until crude reached USD 70-75/bbl, at which point the government would again implement price-caps to protect consumers. Developments in international crude markets have since overtaken the proposal, effectively making it unsuitable, at least for the present.

With the insufficiency of this proposal, actual downstream reform in the time since the government was re-elected has been marginal and piecemeal. The government has, for example, looked, with OMCs, to enforce the quantity restrictions on kerosene - so not more than the set quantity is sold at subsidised prices. Further, as part of the new government's first budget (for FY 2009-10), India's Finance Minister announced approximately USD 2 billion would be set aside to compensate OMCs for their losses under current pricing arrangements. This is a sign that the Gol is beginning to bring off-budget subsidisation onto the official budget itself. The magnitude of this budgeted subsidisation, however, is clearly insufficient, given that oil bond issuance in 2008-09 was close to USD 20 billion.

As part of the budget speech, the Gol announced it would set up a committee to "advise on a viable and sustainable system of pricing petroleum products". ${ }^{19}$ This committee, headed by eminent Indian economist Kirit Parikh, recently released its findings. It sets out a bold vision for reform of the product pricing, including the immediate liberalisation of petrol and diesel markets. The practical impact of this ambitious reform statement (hereafter the "Parikh Report") remains to be seen, and indeed, analysts have reason to be sceptical of its potential influence on Gol policy. Since 2006 the recommendations of several committees convened on this subject, no less bold in scope, have failed to alter the Gol's petroleum sector policies.

Petroleum product pricing policy therefore seems to be in a situation of stasis at present. The moderation of international oil prices in early 2009 took some of the fiscal pressure from the issue, with under-recoveries decreasing slightly and OMCs requiring less financial assistance from the government. Indeed, in the first quarter of FY 2009-10, Indian Oil Corporation, India's largest OMC, recorded one of the largest quarterly profits in its history. In the second half of 2009, however, oil prices again trended strongly upwards, and OMCs again began to record large under-recoveries. Under-recoveries for FY 2009-10 are currently expected to be in the order of USD 15 billion. As long as tight supply-demand balances remain, as expected, a medium-term feature of global crude markets, petroleum pricing will continue to be an issue for India's government, eventually requiring fundamental pricing policy reform, to solve. This issue will be returned to in Chapter 6 .

\footnotetext{
${ }^{19}$ Ministry of Finance (2009), Union Budget, Key Excerpts, 6 July.
} 



\section{Chapter 3. The downstream petroleum sector: policy goals and regulatory environment}

Before growth, trade and investment dynamics of India's downstream petroleum sector can be analysed, it is necessary to outline the policy goals defined by the Gol for the sector. Similarly, the regulatory framework that is in place, both governing the sector and assisting in the achievement of these policy goals, needs to be outlined. ${ }^{20}$

\section{Key policy goals in Indian petroleum refining and retail}

The government of India's $11^{\text {th }}$ Five-Year Plan (covering the years 2007-12) builds on the IEP of 2006 to outline the key policy goals for India's refining and retail sector. These policy goals are fourfold:

1. Market-based pricing throughout the downstream value-chain.

2. Significantly enhanced refining capacity to:

(a) meet growing Indian demand, in order to allow economic growth and standard of living appreciation; and

(b) establish India as a competitive liquid fuels exporter to take advantage of expanding fuels demand in East- and South-East Asia.

3. Ensuring Indian refineries are equipped to process cheap, sour and heavy crudes while still producing internationally-recognised clean-product grades.

4. Maintaining a streamlined, enabling sectoral regulatory framework that stimulates privatesector and joint-venture investment in order to meet goal (2) above.

The issues surrounding Policy Goals 1-3 of the $11^{\text {th }}$ Five-Year Plan are examined elsewhere in this study. For example, Chapter 2 examines the issue of pricing through India's downstream sector. Investment dynamics relating to domestic and export-oriented refining, referred to by Policy Goal 2, are examined in detail in Chapters 4 and 5 respectively. Production of internationally recognised clean fuel grades (Policy Goal 3) is an integral part of these investment dynamics. ${ }^{21}$ Policy Goal 4 will be discussed below in this chapter.

\section{Creating an Indian liquid fuels exporting hub}

Without doubt, the most pervasive issue in the Petroleum and Natural Gas chapter of India's $11^{\text {th }}$ Five-Year Plan is the proposed establishment of India as a world-competitive exporter of refined products - as articulated in Policy Goal 2(b) above. One of the few thrust areas for the

\footnotetext{
${ }^{20}$ Chapter 2 confined analysis primarily to India's four most consumed and subsidised petroleum products - petroleum, diesel, kerosene and LPG. Since this chapter is concerned with policy and regulation in the downstream sector as a whole, this specification will not be made here.

${ }^{21}$ It should be noted here that from the beginning of FY 2010-11 the Gol will enforce Eurolll fuel norms across India, and EurolV norms for all major cities. OMCs' current refineries are being upgraded to allow for this, while all greenfield refineries planned, including OMCs' refineries, are required to comply with production of the highest grade auto fuels (i.e., EuroV and above).
} 
petroleum and natural gas sector as a whole is the "promotion of India as a competitive and economically viable refining destination, to service both the domestic and export markets", a project that rests on the emergence of excess refining capacity in India in the medium-term. ${ }^{22}$ The Plan states that, "the Ministry [of Petroleum and Natural Gas] and companies are taking the initiative to explore the potential for an export hub in India, based on the export opportunities Page | 20 available in Europe and Asia". ${ }^{23}$ The Plan includes a cost-benefit analysis for emerging export refining capacity in India, and concludes that "it is an opportune moment for the domestic refining industry to take on the challenge and to make India a major global refining destination". ${ }^{24}$

India's emergence as a world-competitive liquid fuels export hub depends on large-scale refinery investments by both OMCs and private-sector refiners. Chapter 5 will examine in detail the potential for investment of this scale. Of course, the achievement of high levels of investment in export-oriented refinery capacity is, in turn, partly reliant on the regulatory conditions facing India's downstream sector. The regulatory framework governing the downstream sector is outlined below.

\section{An institutional framework for policy achievement and sectoral growth?}

The key day-to-day role of the Gol in the downstream petroleum sector (outside of its armslength control of OMCs) is to provide an enabling regulatory framework that fosters certainty, timely investment and growth in the sector. In this way, Policy Goal 4 is critical to achieving the other major Policy Goals, and especially the objective to establish India as a refining hub. As the $11^{\text {th }}$ Five-Year plan notes, "actual capacity additions depend on several factors including ... regulatory conditions, duty structure and refining margins" ${ }^{25}$ This section will briefly outline the regulatory framework governing India's downstream sector. It asks: to what extent has the Gol put in place structures and institutions to meet its key policy goals? What is the nature of the regulatory framework governing the downstream petroleum sector?

\section{Downstream regulation}

The Petroleum and Natural Gas Regulatory Board (PNGRB) was established in 2007 as the downstream sector regulator, tasked with regulating the refining, processing, storage, transportation, distribution, marketing and sales of petroleum products and natural gas. It does not, however, authorise refinery infrastructure construction, which is controlled by MPNG, and has no role in market pricing, or pricing policy. The key practical function of the Board relates to (a) its role as court of arbitration in disputes within the downstream sector; and (b) its powers

\footnotetext{
${ }^{22}$ Planning Commission (2007), "Petroleum and Natural Gas Chapter", Eleventh Five-Year Plan, pp. 2-4.

${ }^{23}$ Ibid., p. 3.

${ }^{24}$ Although this is now official government policy, India's Planning Commission has expressed concerns in the past about the development of excess refining capacity in India, given the considerable uncertainty in global product markets. The Commission's concern is that, after very costly investment in additional refining capacity, OMCs may face a situation of structural global excess refining volume, as new capacity emerges in the Middle East, and East- and South-east Asia. These competitiveness issues will be examined in Chapter 5.

${ }^{25}$ Ibid., p. 29.
} 
to release tenders for, and grant of authorisation to lay, build, operate and expand cities natural gas distribution networks.

PNGRB has powers to investigate and litigate against downstream operators for monopolistic behaviour; register entities to market and retail petroleum products, and monitor these entities for cases of adulteration; authorise operators to lay product pipelines, and determine whether pipelines are private- or common-carrier (based on specific criteria); and regulate access to pipelines and pipeline transportation rates. PNGRB also monitors prices through the downstream value-chain, including the adherence to maximum prices set by the Gol; and determines and enforces technical standards and specifications relating to downstream activities.

The establishment of PNGRB is clearly a necessary step in the evolution and maturation of India's downstream sector, providing investors with greater legal certainty and more transparent regulatory oversight and arbitration. Some critics, however, have accused the Gol of establishing a "toothless" PNGRB, without authority over the two key areas of product pricing and refinery investment.

\section{Downstream business environment}

The key aspects of India's business environment are examined below:

(a) Foreign investment policy: India's foreign investment regime has been liberalised significantly since the late-1990s. All private-sector refining projects have automatic foreign investment approval and may be $100 \%$ foreign-owned. In the case of Public-Sector Undertakings, however, foreign equity has to be approved by India's Foreign Investment Promotion Board (FIPB), and cannot exceed $49 \%$ of total ownership. Transactions on the current account are fully convertible, though India retains several controls on capital account convertibility.

While India has considerably increased the access of foreign investors to India's downstream sector through liberalisation of foreign investments approval process, there remain significant "behind-the-border" barriers to investment. While foreign capital projects may be approved fairly simplistically, once approved, projects are required to meet a significant number of changeable, opaque, complex and slow-moving state and Gol authorisations and procedures, for insurance purposes, demographic and environmental impacts, tax compliance, labour standards, etc. This considerable red-tape acts as the key barrier to investment in India. India's Special Economic Zones (SEZs) and Export-Oriented Units (EOUs) (see below) were established largely to assist businesses investing in key industries to skirt this extensive red-tape.

(b) Tax policy: India maintains a relatively cumbersome tax regime compared to similar economies (see, for example, China, and Indonesia). The standard corporate tax rate is high, at $42 \%$, and the maximum personal tax rate is also high, at over $33 \% .{ }^{26}$ Capital gains on assets held for less than three years are taxed as income. Long-term gains are taxed at $20 \%$.

\footnotetext{
${ }^{26}$ Importantly, under India's Income Tax Act, the Gol makes dispensation for a seven-year, $100 \%$ tax holiday on profits derived from undertakings involved in the production or refining of "mineral oils" (i.e., crude) that is established within an allowed timeframe. This clause in the Act was set to expire in 2006, and again in 2009, but has been extended to 2012. The Gol has indicated that it will not extend the clause after 2012, although policy makers have hinted that it might be extended for some time after 2012 in practice.
} 
Most significant however, is the myriad of taxes and duties levied on various products, and imports and exports of products. At the level of the central government, domestically produced petroleum products are subject to a central excise tax, additional excise tax and a special additional excise tax - each of which is different from product to product. At the state level, products are then subject to a VAT, the rate of which is different from state-to-state and from Page $\mid 22$ product-to-product. Products are also subject to a variety of other taxes at the discretion of states - such as, for example, "entry tax" in Uttar Pradesh and Madhya Pradesh, and "Development Tax" in Haryana. ${ }^{27}$ Product is also subject to city taxes and levies, in some locations, e.g., Chennai and Hyderabad. Finally, imported petroleum products are subject to various rates of customs duty, additional customs duty and special additional customs duty, each of which is different from product-to-product.

This complex, changeable and highly-differentiated tangle of taxes and duties reduces margins for downstream marketers and retailers (assuming that all additional taxes cannot be passed onto consumers). ${ }^{28}$ More importantly, as the $11^{\text {th }}$ Five-Year Plan acknowledges, the tax system "creates a business environment fraught with uncertainties, anomalies and geographic complexities". ${ }^{29}$ One of the key components of regulatory reform under Policy Goal 4 in the $11^{\text {th }}$ Five-Year Plan is to streamline, simplify and standardise the petroleum product tax regime to ensure universal tax structures between jurisdictions and products. Thus far, little progress has been made on this issue given the interest of states in protecting their revenue raising autonomy.

(c) Legal environment: India's downstream legal framework is extremely complex, with a variety of often conflicting regulations still in place. India's court system in general is prone to lengthy delays, with most courts lumbered with numerous unsettled dispute cases. In ordinary cases, foreign downstream investors have to manoeuvre through a myriad of rules and certifications to obtain the estimated seventy separate approvals needed for setting up business in India (unless it is operating within a SEZ or EOU). ${ }^{30}$ Meanwhile, delays in hearings and judgements are routine.

There is a perception within the international business community that, in general, India lacks effective respect for the sanctity of contract. However, there are an increasing number of agreements that provide for arbitration, such as through the International Centre for Alternative Dispute Resolution or, in serious cases, through multilateral conventions like the Geneva Convention. The establishment of the PNGRB, in particular, has added a degree of certainty and oversight to downstream business practice. On the whole, the legal system governing India's downstream sector is in a state of transition, with the end goal of being more responsive to the needs of foreign businesses and the private sector. Currently, however, several shortcomings, primarily in terms of efficiency of procedure, exist in the legal system. ${ }^{31}$

\footnotetext{
${ }^{27}$ A standardised VAT was introduced in India at the beginning of FY 2005-06, however almost half of India's states, at which level it is levied, have simply refused to put this in place. Many others that have put it in place have reserved the right to levy other sales taxes, thus undermining the basic premise of a universal VAT.

${ }^{28}$ Some states have "irrecoverable taxes" on the sale of petroleum products, meaning these taxes cannot be passed on in the form of higher prices. Such taxes are therefore levied on the revenues of the vendor from the sale of the product.

${ }^{29}$ Planning Commission (2007), "Petroleum and Natural Gas Chapter", Eleventh Five-Year Plan.

${ }^{30}$ Business Monitor (2009), "India Oil and Gas Report, Q3 2009”, June, p. 43.

31 Ibid., p. 44.
} 


\section{Fostering investment: Special Economic Zones, Export-Oriented Units}

In an effort to encourage investment in key industrial sectors, the Gol, in partnership with state governments, has introduced cornerstone industry policy that seeks to establish SEZs and EOUs. While somewhat different in nature, both SEZs and EOUs are designed to: (a) reduce the redtape associated with investing in India; and (b) provide certain tax and income concessions for businesses investing in key export-oriented industries. Petroleum product refining and processing is one of the sectors that are targeted by the SEZ and EOU programmes.

(a) Special Economic Zones: Indian SEZs are legally deemed foreign territory in order to skirt India's multiplicity of domestic duties and tariffs and its numerous controls and authorisations. SEZs may be established either by state and central governments in collaboration, or by corporations on request to state and central governments. The major condition, amongst several others, for the location of operations in a SEZ, or the bid to have a SEZ designated around the location of operations, is that companies must earn greater than $60 \%$ of revenues in foreign currency. Because of the still-developing nature of refined product export in India, downstream companies are currently active in only 4 SEZs out of a total of over 300: Mangalore SEZ, Gujarat (i.e., Jamnagar) Hydrocarbon and Energy SEZ, and Kochi and Mundra Ports.

The key incentives and facilities offered to investors within SEZs are:

- "Single window" clearance of investments and projects for both central and state government approvals, controls and clearances.

- Duty free import of goods for development, operation and maintenance of SEZ units.

- $100 \%$ income tax exemption on companies' export income for first five years, and $50 \%$ exemption for the five years thereafter.

- No restriction on external commercial borrowing up to USD 500 million in a year through recognised banking channels.

- Exemption from central government sales tax and service tax, and exemption from state government sales tax as well as various other duties levied by states.

(b) Export-Oriented Units: A corporation exporting over $75 \%$ of production is entitled to apply to become an EOU, a corporation-centric designation, to complement geography-centric SEZs (which often involve a number of companies). EOUs receive many of the same benefits as corporations located in SEZs, such as "single-window" investment and project clearance and income tax exemption. Many EOUs operate in SEZs. However the EOU designation is intended largely for corporations whose operations are geographically spread, and not concentrated in a small area. Under the EOU scheme, corporations are allowed to purchase all goods required to produce exports free of all duties - excise, customs duties, states levies, etc.

As has been mentioned, RIL's massive $660000 \mathrm{bbl} / \mathrm{d}$ Jamnagar I refinery was established as an EOU. In early 2009, however, RIL requested that the EOU designation be removed. This was a result of rapidly falling international product demand in the wake of the global economic slowdown; and falling crude prices, which temporarily made domestic retail of sensitive petroleum products commercially viable for RIL. The move away from EOU status was therefore caused by a combination of external events rather than a fundamental shift in the business model for RIL's refining operations. 


\section{Assessing India's downstream sector regulatory framework}

The regulatory framework and business environment in India's downstream sector is evolving to increasingly cater to the needs of private-sector investors (e.g., in the relaxation of foreign investment controls), however there remain considerable weaknesses. As mentioned, these

Page | 24 weaknesses stem largely from the institutionalised red tape cluttering India's legal, regulatory and financial systems. The establishment of single-window project and investment clearance through SEZ and EOUs has remedied this condition to some extent. However, the very process of establishing SEZs and EOUs is itself quite complex, expensive and time-consuming. Further, SEZs have, in their principle, received a great deal of criticism in India and externally:

- A concerted grass-roots movement by various groups in India has called loudly for a moratorium on the establishment of new SEZs, which effectively cede land away from India. This has placed the future of the SEZ policy in doubt.

- The World Bank has criticised the Gol's practice of locating SEZs in underdeveloped regions to foster development, rather than in strategic trade facilitating locations. According to the World Bank, even SEZs established in coastal districts (such as Jamnagar) focus activity away from the coast itself in order to develop inland districts. ${ }^{32}$

- SEZ and EOU programmes have been censured for creating perverse incentives in Indian petroleum product markets. Conducting business as an EOU, or within a SEZ (as RIL's Jamnagar complex does) requires corporations to look to export product as much as possible to meet the conditions of operation. The situation currently exists, therefore, that OMCs are required to import petroleum and diesel to meet domestic product demand (and pay customs duty on theses imports) while these same products are simultaneously exported by private-sector refiners.

To this extent, it is increasingly necessary to reform the domestic regulatory environment as a whole, rather than to rely on flawed "exceptionalist" export promoting policies and programmes. This is likely to be a painstaking and drawn-out process. In the downstream sector, however, the Gol can make a handful of key reforms that are likely to significantly improve the business environment. The establishment of the PNGRB, for an example of such strategic reform, has provided investors with added legal certainty, and more transparent regulatory oversight and arbitration. Of most pressing concern on this reform agenda might be the restructuring of the muddled system of taxes, duties and levies on petroleum products. As promised in the $11^{\text {th }}$ Five-Year Plan, the Gol should move beyond scoping studies of downstream tax reform to concretely implement the unification of separated state product markets, to properly standardise the VAT, and to remove the multitude of state tax anomalies and exceptions.

This would, of course, have to be undertaken in collaboration with state governments - a significant undertaking. Tax reform is crucial, however, to reduce what the Planning Commission calls "the uncertainties and geographic complexities" faced by investors in India's downstream sector. Another key institutional pillar for well-functioning product markets, for example, is the establishment of a petroleum product exchange. By substantially reducing transaction costs, increasing competitiveness and efficiency and greatly augmenting market transparency, the creation of such a market exchange is a crucial step in establishing the institutional basis for India to become a refined product trading hub.

\footnotetext{
${ }^{32}$ World Bank (2008), World Development Report 2009, November, pp. 23-25.
} 
India's regulatory framework governing the downstream petroleum sector is in a state of transition. Currently, downstream investment in India is promoted less by competitive advantages created by the Gol, and more by the inherent comparative advantages of the country itself. India's large and rapidly growing domestic petroleum product market is, with the similar emergence of China, a perhaps unprecedented market opportunity for the global oil and petroleum industry. India simultaneously boasts low unit labour costs and the demographic potential for a large and capable skilled/managerial work force. Geographically, India's West Coast is strategically located directly facing the Persian Gulf across the Arabian Sea, from where over $40 \%$ of the world's seaborne crude oil originates. In addition, the Middle East's refined product demand is growing rapidly. The country is also strategically placed, straddling key global crude producers in the Middle East and the growing consumption centres of East- and SouthEast Asia.

While the distinctive combination of India's comparative advantages puts it in a reasonable position to attract downstream private-sector investment, the Gol nevertheless needs to streamline the regulatory framework governing the downstream sector, to make it more conducive and open to timely investment by private-sector energy firms. Chapter 5 will examine in more detail the potential for India to do so, and to thereby establish a global liquid fuels trading centre within India's borders over the medium-term. Chapter 4 examines the patterns of growth and investment in the OMC sector that makes up the great majority of India's downstream petroleum sector, in terms of market share, refining capacity and investment. As will be discussed, the dynamics of this sector have much more to do with the nature of government involvement with the key companies than with domestic comparative and competitive advantages or rates of return on investment. 



\section{Chapter 4. India's oil marketing companies}

India's publicly-owned OMCs are the dominant players in the country's downstream petroleum sector. In fact, they are among India's top twenty largest corporations (by sales), and each is a member of the Fortune 500 list of the world's 500 largest companies. India's largest OMC India Oil Corporation Limited (IOCL) - is the country's largest corporate entity, by sales. The great majority of Indian consumers and industries, especially the fertilizer and growing petrochemical industries, access petroleum products through these OMCs. It is impossible to understand dynamics within India's downstream petroleum sector therefore without first understanding roles and operations of India's three OMCs within this sector. In the same way, it is impossible to outline the potential future of the Indian downstream sector in the mediumterm without understanding the prospects for $\mathrm{OMC}$ evolution and investment.

This chapter provides an account of the nature and prospects of the OMC sector and its implications for the evolution of India's downstream industry. It concentrates in particular on the ability of OMCs to invest in refinery capacity at a sufficient rate to: (a) adequately meet growing Indian demand; and (b) to position India as a world-leading refined products exporter into the future. In order to outline product market conditions, Chapter 2 confined analysis to India's four most consumed and subsidised petroleum products - petroleum, diesel, kerosene and LPG. Since this chapter is concerned largely with refinery investments in general rather than pricing arrangements specifically, this exception will not be made here.

\section{OMCs' relations with the Gol}

As well as being the dominant entities in India's downstream sector, OMCs are the key link between the petroleum industry and current government downstream policy, especially pricing policy. By supplying petroleum products at a set price, OMCs are the tools of the Gol's liquid fuels access policy. As a result, OMCs have borne the full burden of the Gol's control of product prices. Importantly, by absorbing the losses inherent within the current system of market regulation, OMCs define the remaining market-space within which other downstream actors, such as private-sector refiners, may operate and invest. This chapter seeks to outline the nature of this space.

OMCs are majority-owned by the Gol and formally come under the jurisdiction of MNPG. From day-to-day they are run in a corporatised and independent fashion, according to, nominally, world-best-practice commercial procedures and corporate governance standards. The Gol, however, has considerable control over OMCs' long-term strategy and investment programmes. At the beginning of every financial year, OMCs sign a Memorandum of Understanding with MNPG which outlines agreed upon production and sales targets, investment expenditure plans and specific delegations of duties. OMCs are also required to submit investment plans to the Planning Commission for approval for each of India's Annual Plans as well as its Five-Year Plans. The Planning Commission retains some influence over the decisions made by OMCs' Executive Boards, however not to the same degree as MPNG. Through this process of consultation and approval, the Gol is able to effectively control the nature and direction of OMCs' commercial activities and investment expenditures over time. An effective contract exists between the Gol and OMCs. The Gol explicitly guarantees the solvency and commercial integrity of OMCs under all market conditions. OMCs, in return, (a) supply markets at government-determined prices; 
and (b) actively look to invest to ensure refining, retailing and infrastructure capacity meets rapidly growing Indian product demand.

Chart 6. Gol stake in OMCs

Page | 28

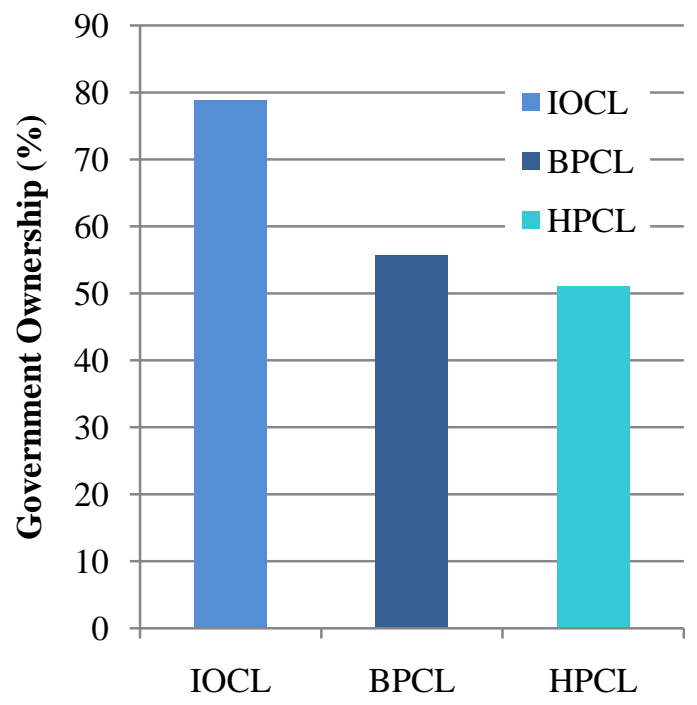

Source: Company Financial Statements.

This guarantee has come into play significantly in recent years. In order for OMCs to not only remain solvent, but to be in a position to invest in additional capacity and infrastructure in a timely fashion, the Gol has needed to repeatedly "bail-out" these firms for their losses under the current product pricing regime. As will be examined, this explicit guarantee has significant implications for the ability of OMCs to raise capital and invest over time, and therefore for the evolution of India's downstream industry as a whole over time. While OMCs' Executive Boards have fairly close ties to the Gol bureaucracy, these companies have no formal role in policy making. Disputes between OMCs and the government over policy (such as the Gol's policy to begin strictly managing product prices early in the last decade, for example) can be acrimonious and long-lasting.

\section{Structure of the OMC sector}

India's three key OMCs are (in order of size by sales):

- Indian Oil Corporation Limited (IOCL);

- Bharat Petroleum Corporation Limited (BPCL); and

- Hindustan Petroleum Corporation Limited (HPCL).

These three OMCs dominate the Indian downstream sector - both in retail and (to a lesser extent) refining. As Chart 7 shows, OMCs together account for over $50 \%$ of domestic refining capacity - and over $80 \%$ of this if RIL's single very large (and, until recently, export-oriented) Jamnagar complex is excluded. They account for $98 \%$ of operational retail outlets. While RIL and Essar have established a retail presence in the Indian market, as mentioned above, these outlets were closed as crude costs increased rapidly beyond retail prices. As crude prices fell sharply in 
the first half of 2009 both Essar and RIL began slowly re-opening retail outlets - however, the rise in international crude prices since mid-2009 has effectively halted this process for the moment. $^{33}$

Table 1. Major downstream players

\begin{tabular}{|l|l|l|l|l|l|l|l|}
\hline & IOCL & BPCL & HPCL & RIL & Essar & M'lore & Chennai \\
\hline Refining (mb/d) & 1.2 & 0.6 & 0.25 & $1.24^{34}$ & 0.22 & 0.2 & 0.19 \\
\hline Retail outlets & 18140 & 8389 & 8539 & 800 & 1200 & 0 & 0 \\
\hline
\end{tabular}

Source: IEA analysis.

As shown in Table 1, the three key OMCs share Indian refining and retail with a very small number of other industry players. These include two other small publicly-owned corporations. Mangalore Refinery and Petrochemicals Corporation Limited (MRPL) is Oil and Natural Gas Corporation (ONGC)'s downstream subsidiary, which operates a single (although quite large) integrated refinery and petrochemicals plant in Mangalore. Chennai Petroleum Corporation Limited (CPCL) is a subsidiary of IOCL, and operates two small refineries in Tamil Nadu State, as well as small petroleum product marketing operations in Southern India.

Chart 7. Refining market share

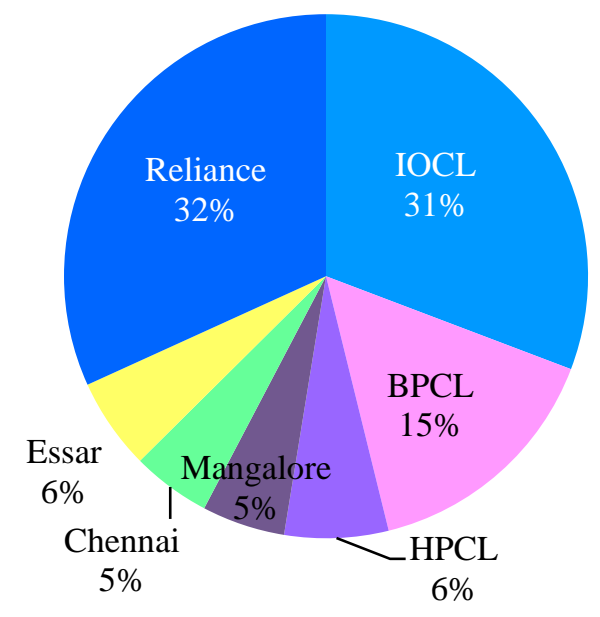

Source: IEA analysis.

RIL and Essar, the current private-sector players, both have highly ambitious downstream expansion plans in refining, which seek to fundamentally change the landscape of refining in India. The market share in refining of these two private-sector operators has increased rapidly and markedly, especially with the commissioning in early-2009 of RIL's giant $580000 \mathrm{bbl} / \mathrm{d}$ expansion to its Jamnagar complex in Gujarat, which has since become the world's largest refinery complex (with a capacity of $1.24 \mathrm{bbl} / \mathrm{d}$ ). Essar operates a single $220000 \mathrm{bbl} / \mathrm{d}$ refinery

\footnotetext{
${ }^{33}$ Chart 8 assumes RIL and Essar's retail market share is nil, as private-sector auto fuels retail is viable under current government pricing conditions only if world crude prices remain between USD 55-60/bbl.

${ }^{34}$ This figure includes Jamnagar II commissioned in late-2008. RIL's weight in Indian refining is somewhat overstated by a simplistic comparison of refinery capacity: RIL still operates only one (albeit very large) refinery, a significant proportion of whose product is exported.
} 
at Vadinar, very close to Jamnagar in Gujarat, with plans to increase refining capacity to $680000 \mathrm{bbl} / \mathrm{d}$ by 2012. These two firms' investments will be examined in more detail in the following chapter on international refining in India.

Chart 8. Retail market share

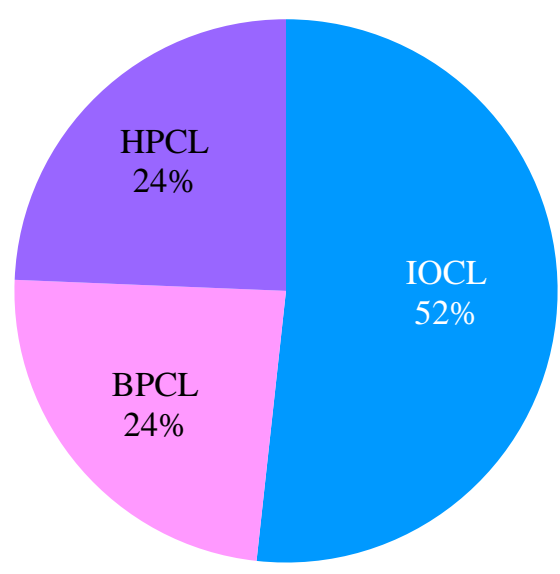

Source: IEA analysis.

With extensive domestic marketing and retail networks, and a government-determined function to meet growing domestic petroleum product demand, OMCs' operations are overwhelmingly centred on supplying the Indian market. Each currently exports, on average, as little as $50000 \mathrm{bbl} / \mathrm{d}$ of product (from total OMC refining capacity of about 2 million bbl/d). In contrast, RIL and Essar's refining operations are designed to supply both international and domestic product markets. Recent data indicate that both private-sector refineries in Gujarat are currently producing an even balance of output supplying the Indian market and that destined for export.

It should be stressed that, despite price controls, RIL and Essar are able to supply Indian markets (either domestic retail markets or OMCs' established base of customers for industrial fuels and lubricants) by selling refined products wholesale to OMCs from the refinery gate. Domestic refinery-gate prices are determined on a trade-parity basis. Private-sector refiners can therefore freely supply the Indian auto fuels retail market through OMCs while gaining market-based refining margins and without under-recovery. By absorbing the commercial losses inherent in the current retail system, OMCs therefore create a space in Indian product markets in which the private-sector can conduct commercially viable, profitable and sustainable business, despite the existence of price controls.

\section{A brief description of India's three OMCs}

(a) Indian Oil: IOCL is the giant of India's hydrocarbons industry. Its refining and retail operations are the focus of IOCL's business, although it maintains highly diversified commercial operations including significant upstream Exploration and Production (E\&P) (in India as well as internationally) and petrochemicals and fertilizer businesses. IOCL's large 
size and diversified operations have meant that it has weathered the Gol's product pricing policies somewhat better than the smaller OMCs. In the downstream sector IOCL has over $50 \%$ market share in marketing and retail. It also has an impressive portfolio of refineries, making up about $32 \%$ of Indian refinery capacity. IOCL operates 10 refineries across India with a combined capacity of about 1.2 million $\mathrm{bbl} / \mathrm{d}$.

(b) Bharat Petroleum Company: BPCL is India's second largest OMC by sales, marginally larger than Hindustan Petroleum Corporation, and approximately the $300^{\text {th }}$ largest corporation in the world. As shown in Table 1, BPCL operates a retail network of over 8000 outlets - the smallest retail presence of the major OMCs. Compared to its small automotive fuel retailing operations, however, BPCL has large industrial and jet fuel marketing operations. This is advantageous for BPCL as jet fuel and other industrial products fall outside the Gol's price controls. BPCL maintains three refineries: its $300000 \mathrm{bbl} / \mathrm{d}$ Mumbai refinery; the $150000 \mathrm{bbl} / \mathrm{d}$ Numarlingarh refinery in North-Eastern India; and the $150000 \mathrm{bbl} / \mathrm{d}$ Kochi refinery in Southern India.

(c) Hindustan Petroleum Corporation: HPCL is the smallest of India's three key OMCs, although it is still one of the fifteen largest corporate entities in India. HPCL has a slightly greater auto fuels retail presence than BPCL - also with over 8000 retail outlets. Its large exposure to the auto fuels retail market has meant HPCL has been significantly affected by price controls. HPCL's refining capacity is significantly less than both $I O C L$ and BPCL. It operates two refineries - one located in Mumbai and one at Visakh on the East Coast, with capacities of $120000 \mathrm{bbl} / \mathrm{d}$ and $230000 \mathrm{bbl} / \mathrm{d}$ respectively. HPCL's production capacity at these two refineries has expanded steadily through a number of recent capacity expansion projects. The company's Mumbai refinery is distinctive as a lube-specialist refinery, with India's highest lube production capacity conferring HPCL a dominant market share in this unregulated product segment.

\section{The challenge facing OMCs}

Indian demand for petroleum products is growing rapidly. Close to one million cars were sold per month in India in 2009. In 2008, Indian product demand was approximately $2.9 \mathrm{mb} / \mathrm{d}$. Demand is expected to grow at up to $4 \%$ per year in the following years - meaning in the five years to 2014 demand is forecast to approach $3.7 \mathrm{mb} / \mathrm{d}$, an increase in demand of $800000 \mathrm{bbl} / \mathrm{d} .{ }^{35}$ The significant challenge facing OMCs is to add refinery capacity to meet this strongly growing domestic demand. At the same time, OMCs have a commercial and government-driven (although secondary) imperative to expand petroleum product export capacity. These two commercial obligations require significant large-scale investment in capacity by OMCs currently and into the future. OMCs are, however, under significant financial strain as a result of the Gol's retail pricing policies; in fact, they remain effectively insolvent. The key question, therefore, is: to what extent can OMCs achieve the capacity expansion necessary to meet growing demand given their current commercial positions. This question will be examined in detail below.

\footnotetext{
${ }^{35}$ See EIA (2009), India Country Report, p. 1.
} 


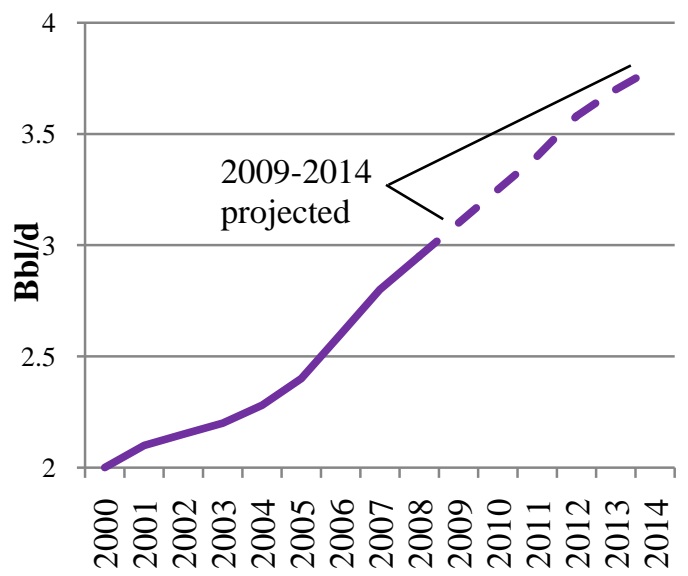

Source: IEA Medium-Term Oil Market Report (MTOMR).

\section{OMCs' financial performance}

As a result of retail pricing controls, the $\mathrm{OMC}$ sector as a whole performed very poorly from a financial perspective in FY 2008-09. Table 2 lists the key financial indicators for each of India's three OMCs from FY 2007-08 to FY 2008-09. In general, it tells a worrying story. As Table 2 shows, unsustainably weak cashflows were a significant issue for OMCs, with both IOCL and $\mathrm{HPCL}$ recording negative operating cashflows (and BPCL recording negative net cashflows) in FY 2008-09. The financial position of each OMC is examined in more detail below.

\section{IOCL}

The relative health of IOCL's balance-sheet (compared to smaller OMCs) is apparent when comparing gross operating margins. In FY 2008-09 IOCL achieved gross operating margins around $50 \%$. These are high compared to global industry averages, and extremely high compared to the gross margins of India's other OMCs. Worryingly, however, net cashflow for FY 2008-09 is almost zero. In fact, net cashflow figures reflect a gross operating cashflow of negative USD 4.7 billion. This entirely unsustainable situation is not altogether surprising given pricing arrangements. Indeed, over the course of FY 2008-09 IOCL received approximately USD 8 billion from the Gol in oil bonds specifically to counteract the cashflow problems resulting from controlled prices.

The Gol's significant support for IOCL in 2008-09 has successfully bolstered the company's balance-sheet and left it well-placed for further expansion. IOCL is unburdened by large amounts of debt. Its debt-to-equity ratio is healthy, at just greater than one. IOCL's interest payment burden, however, has increased precipitously in the last year. In FY 2008-09, IOCL's profit covered total interest payments by a magnitude of about three, compared to a magnitude of greater than nine in FY 2007-08. 
Table 2. OMCs key financial indicators

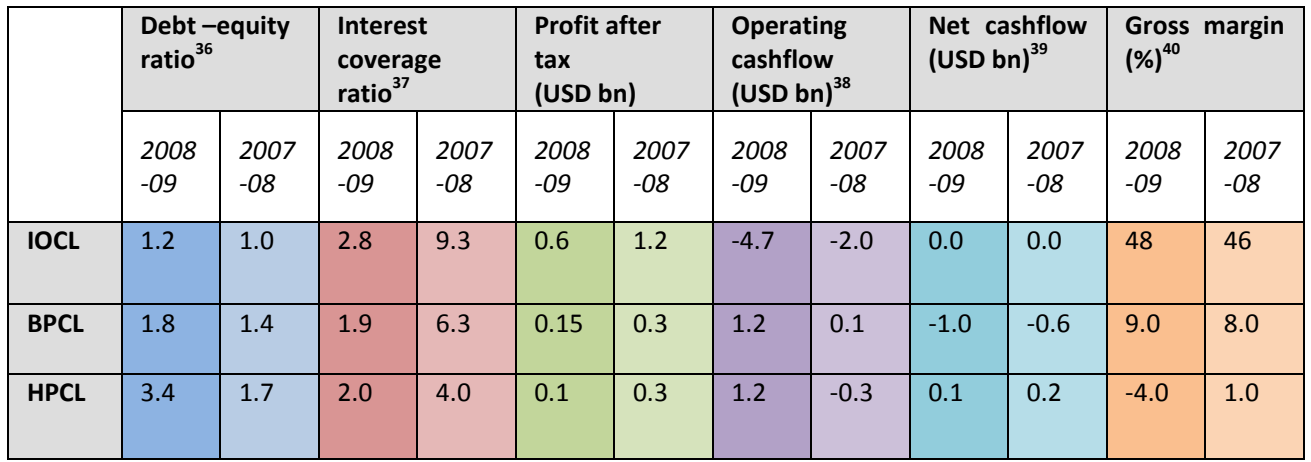

\section{$B P C L$}

With less diversified operations than IOCL, BPCL has fared badly recently. In FY 2008-09, BPCL's gross operating margin was below $10 \%$, compared to a global industry average of close to $40 \%$. Not surprisingly, net cashflow was negative USD 1.2 billion in FY 2008-09, further down from around negative USD 700 million in FY 2007-08. Consistent and heavily negative net cashflow means BPCL has failed to generate necessary operating revenue over time. The provision of USD 3.2 billion in oil bonds from the Gol (equivalent to over $12 \%$ of total sales), however, helped BPCL to post a small profit in FY 2008-09. This profit was almost entirely absorbed by interest payments on accumulated debt. Heavily negative net cashflow also means that BPCL has been forced to rely on debt financing for investment. In FY 2008-09, debt-to-equity was almost double the levels considered to be optimal. As mentioned, BPCL's growing indebtedness has meant its weak yearly profits are used almost entirely to cover its growing interest burden, with the company's interest coverage ratio falling to below 1.9.

\footnotetext{
${ }^{36}$ This ratio gives an indication of a corporation's indebtedness - and thereby (a) its interest burden and (b) its ability to raise further debt capital for investment - by comparing accumulated debt and equity at the end of any given financial year. Ratios of around 1 are considered optimal, while those $>4$ are considered risky.

${ }^{37}$ This ratio is a measure of a company's ability to honour its debt payments. It compares a company's profit with its interest burden. When profit-interest is less than 2.5 companies are at high risk. Ratios $<1$ indicate that a company will not generate enough cash to meet its interest obligations.

${ }^{38}$ Operating cashflow refers to the amount of cash a company generates from the revenues from core operations, excluding net revenues from long-term investment on capital items, investment in securities or cash transfers.

${ }^{39}$ Net cashflow refers to total cash generated by a company from all activities, including operating cashflow; revenue received from the sale of long-life assets; capital expenditure; or cash received from the issue of debt and equity, or paid out as dividends.

${ }^{40}$ Gross margin is the relationship between a company's profit and its sales revenue, similar to its markup. It calculates the proportion of sales revenue that is profit. Gross margins of $30 \%$ are considered healthy.
} 


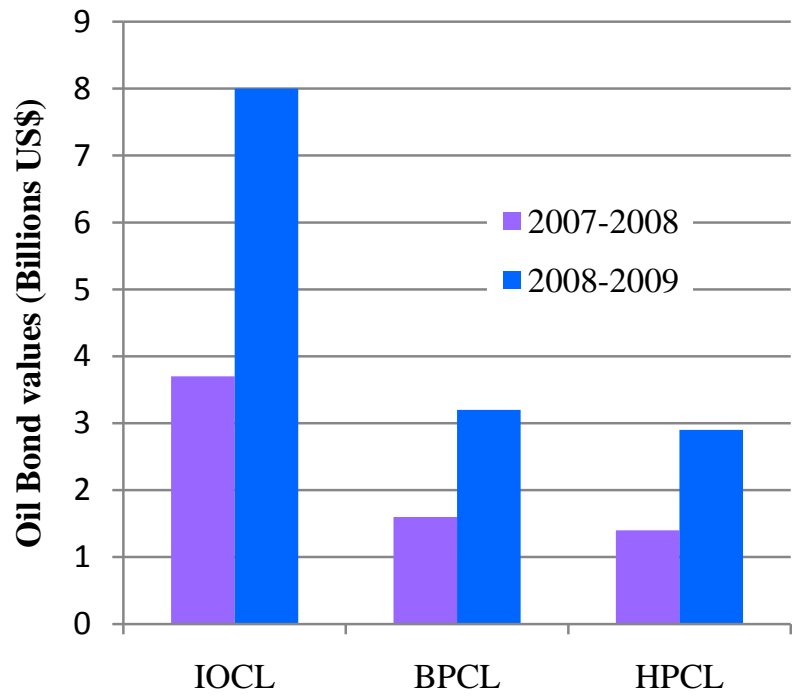

Source: Company Financial Statements.

\section{$H P C L$}

HPCL's relatively undiversified refining and retail business has also fared badly in recent years. In FY 2008-09 HPCL maintained a negative gross operating margin, a rare and unsustainable situation, and a direct consequence of the Gol's product pricing policies. Unlike IOCL and BPCL, HPCL's net cashflow from all activities in FY 2008-09 was marginally positive (as a result of its sale of assets). HPCL's debt burden has increased markedly in recent years. The company's debt-to-equity ratio has increased to more than triple the level considered optimal, while the ability of HPCL's current profit to cover interest payment obligations halved from 2007 to 2008. Oil bonds issued to HPCL by the Gol in FY 2008-09 amounted to close to USD 3 billion.

\section{OMCs' investment programmes}

Despite their dire financial performance, OMCs have developed, financed and are implementing ambitious capital investment programmes in distribution and retail infrastructure, and importantly, in considerable additional refining capacity. The Gol's demonstrated willingness to back OMCs as instruments of public policy, combined with its support for OMCs' finances through the issuance of oil bonds have provided these firms with a great deal of leverage when raising capital in debt and equity markets. Further, it has provided OMCs with a level of operational and commercial flexibility in which short-term rates of return on investment are not entirely compelling. As will be shown, the OMC sector is therefore defined by heavy-handed regulation and poor commercial performance, yet robust investment, capacity addition and growth. The investment programme of each OMC is examined in turn below, with a focus on refinery capacity additions. The implications of the current situation are also analysed in this chapter. 


\section{IOCL}

IOCL has formulated a massive downstream investment and expansion programme to strengthen its core business and allow for rapidly growing product demand in India. Its relatively debt-free balance sheet and the continued backing of the Gol are key in this regard. In 2008-09, IOCL's investment expenditure totalled USD 2.24 billion, including approximately USD 1.2 billion on refinery capacity expansion and yield and quality improvements, and marketing operations. This compares to profit after tax of USD 900 million in the same year. Under its medium-term investment strategy to March 2012, IOCL plans to invest USD 9.24 billion. This includes USD 5.1 billion on refinery capacity expansions, meaning close to $60 \%$ of IOCL's total planned investment expenditure budget is dedicated to refining. IOCL's major downstream investment projects include:

- The construction of a large, state-of-the-art greenfield $300000 \mathrm{bbl} / \mathrm{d}$ refinery at Paradip in Eastern India, with a total cost of USD 4 billion. The project aims to meet the current deficit of light-middle distillates in Eastern India, and is scheduled to be completed by late-2012.

- IOCL's Panipat refinery in Haryana is being expanded by $60000 \mathrm{bbl} / \mathrm{d}$ to meet the growing product deficit in the high-demand North-West region of India, with a cost of USD 300 million. A long-distance pipeline linking the Panipat refinery with Mundra port in Gujarat State is also part of this project.

- IOCL is investing heavily in petroleum quality upgrade projects at its Gujarat, West Bengal, Haryana, Bihar and Assam refineries to ensure each of these facilities produces at least EurolV fuel quality grades by $2011 .{ }^{41}$ These upgrades will come at a total cost of about USD 2.4 billion.

\section{$B P C L$}

Despite the fragile state of its balance sheet, BPCL is nevertheless expanding capacity to meet growing demand and enhance its market share (especially in automotive fuels) through a comprehensive investment programme. This investment programme is only possible through the continued financial support and explicit backing of the Gol. With high levels of debt, a growing interest burden, weak profits and negative net cash flows, BPCL, on the strength of its balance sheet, would likely be unable to raise the significant capital necessary for large-scale and ongoing capacity expansions. The regular extensions of oil bonds to BPCL (amounting to close to USD 5 billion since 2007) not only smooth-over major cashflow issues, bolster the company's balance sheet and ensure BPCL can service its debt in the short-term, they also create confidence within financial markets that BPCL will remain commercially viable over time.

At the centre of BPCL's investment programme is the greenfield construction of its Bina refinery complex in Central India - a joint venture between BPCL and Oman Oil Company. The Bina complex will have a capacity of $130000 \mathrm{bbl} / \mathrm{d}$, and is scheduled for completion in 2011. Also under construction are crude receipt and dispatch facilities on the coast at Jamnagar, and a 935-kilometre cross-country crude pipeline from Jamnagar to Bina. BPCL has invested a total of

\footnotetext{
${ }^{41}$ As mentioned above, the Gol has mandated the sale of European Emissions Standards' EurolV fuels in urban areas and Eurolll fuels in rural areas by 2010-11. In Europe, Eurolll was phased out in 2005, while EurolV was phased out in 2008-09. Clearly, OMCs' refineries currently being upgraded to produce EurollI/IV are some way behind complete export readiness. All OMCs' greenfield refineries currently under construction, however, are being built to produce world-leading clean fuels.
} 
over USD 1.2 billion in the Bina project. BPCL is also undertaking a USD 1 billion upgrade of its Kochi refinery, to be completed in 2011. This project will add around $50000 \mathrm{bbl} / \mathrm{d}$ of capacity, as well as upgrade product qualities to EurolV standard. As a part of the upgrade BPCL is investing to upgrade publicly-owned Kochi port to allow mooring of Very Large Crude Carriers and to establish an undersea pipeline link to the refinery, as well as the addition of significant Page | 36 extra crude and product storage capacity. BPCL's Mumbai refinery is also undergoing a comprehensive upgrade to increase efficiency and fuel qualities, however no significant new capacity will be added. Finally, all refineries will be upgraded by mid-2011 to allow the production of at least Eurolll fuel grades.

BPCL has therefore been capable of significant investment in spite of persistently very weak commercial fundamentals. With the currently proposed Stage II of its Kochi refinery upgrade the company will have almost doubled its 2008 refining capacity through various investments and expansions costing close to USD 5 billion.

\section{HPCL}

HPCL has a slightly less ambitious investment programme than either IOCL or BPCL. Nevertheless, investment expenditure remains decidedly expansionary to capitalise on growing Indian product demand. The centrepiece of HPCL's investment expenditure is the construction of the Guru Gobind refinery at Bhatinda in Punjab province - with an initial capacity of almost $200000 \mathrm{bbl} / \mathrm{d}$, and costing approximately USD 3 billion. The refinery is a joint venture between HPCL and Mittal Energy Investments - a subsidiary of the L.N. Mittal Group of companies - with each partner taking a $50 \%$ stake in the venture. A 900-kilometre pipeline from Mundra Port to the refinery at Bhatinda will also be built as part of the project. The project is scheduled for completion in 2012, and will almost double HPCL's current refining capacity. Guru Gobind is intended to ease product availability in the company's growing marketing network in India's fast-growing Northern regions. In order to ease product tightness in diesel and jet fuel, HPCL is increasing distillate production by close to $60000 \mathrm{bbl} / \mathrm{d}$ across its refineries, at a total cost of USD 600 million. Both currently operational refineries are being upgraded to allow the production of EurolV auto fuels.

\section{Assessing OMCs: do OMCs provide for growth in India's downstream sector?}

The foregoing analysis of India's OMCs paints a mixed but extremely interesting picture. OMCs have clearly suffered considerably at the hands of the government-imposed restrictions on retail prices. For each, operating cashflows in 2008-09 were negative, and significant government support was required to merely keep them solvent and marginally profitable. Received wisdom would suggest that, with OMCs' commercial imperatives and revenue earning potential undermined by heavy-handed market regulation, the ability of companies to undertake timely, large-scale investment to meet rapidly growing domestic demand would be thoroughly undermined. With dried-up cash flows and managed end-user prices, the incentive for investment, it may also be argued, is removed.

This, as shown, is not the case - something which is clear when the OMC sector is analysed as a whole. Despite decidedly weak commercial performance and poor balance sheet fundamentals, OMCs have, together, put in place expansive investment programmes that look likely to more 
than cater for robust Indian petroleum product demand growth in the medium-term. It may be concluded, therefore, that the OMC sector is defined by heavy-handed regulation and poor core commercial performance, yet robust investment, capacity addition and growth.

Indian product demand is expected to grow from an expected total of 3 million bbl/d in 2009 by approximately 700000 to 3.7 million bbl/d in the five years to 2014. OMCs will add about $600000 \mathrm{bbl} / \mathrm{d}$ of additional capacity in greenfield refinery projects alone by 2012 . This does not include (a) OMCs extensive brownfield capacity expansions and upgrades that are described above; (b) the ambitious investment plans of private-sector refiners; or (c) existing surplus refinery capacity which has emerged since the start-up of RIL's Jamnagar II refinery in early 2009. Given that, in the OMC sector, product that is surplus to the demands of the domestic market is exported internationally, growing OMC refining capacity bodes well for India's goal to develop into a major exporter of petroleum products.

In fact, OMC's unique relationship with the Gol has dramatically enhanced, rather than hindered, the investing potential of these companies and therefore the dynamic growth of India's downstream petroleum sector. The explicit guarantee by the Gol that OMCs will be kept solvent and profitable over time lends OMCs huge advantages when raising capital for investment in financial markets. Potential financiers may be certain that, despite what may be high levels of corporate debt and weak profits, government support will ensure that OMCs debt and interest obligations are met. This is clear in the corporate credit ratings of OMCs. Despite very weak financial fundamentals, $I O C L, B P C L$ and $H P C L$ were each awarded a AAA credit rating by S\&P (through its Indian subsidiary CRISIL) in 2009, because "the public policy role performed [by OMCs] makes it binding that the government of India support the company and its stakeholders, including lenders". ${ }^{42}$

Perhaps most significantly, the willingness of the Gol to consistently "bail-out" OMCs in return for reliable market supply and strong investment inevitably breeds a soft investment constraint for these firms. With the government standing ready to absorb their losses, concerns of the rate-of-return of various investments are far less compelling for OMCs than for truly commercial actors, a situation which typically results in the rapid investment (or potentially overinvestment) that has been witnessed in the last decade.

From a policy outcomes perspective, the current system of inter-relations between the Gol, OMCs and product markets is highly successful. With OMCs' assistance, the Indian government has been able to pursue its official policy of providing affordable energy for India's developmental needs and its significant poor population. At the same time, by absorbing OMCs losses under this system and explicitly guaranteeing their operations, capital financing and investments, the government has created an investment climate for OMCs which has resulted in robust sectoral capacity expansion and growth. The key issue surrounding the OMC sector is therefore not one of lacklustre commercial operations in an environment of heavy-handed regulation and price manipulation. In fact, one may conclude that the current system has provided for a great deal of sectoral dynamism. Instead it is a fiscal question. For how long can the Indian government continue to spend hundreds of billions of Indian Rupees on perpetuating the solvency and investing potency of OMCs that is required under current product pricing arrangements?

\footnotetext{
${ }^{42}$ See for example, CRISIL (2010), Hindustan Petroleum Corporation Limited: Debt Instruments and Bank Facilities, January.
} 


\section{Public- versus private-sector refining}

With strong investment expenditure as a result of relatively easy access credit and soft investment constraints, and OMCs' refining capacity expanding rapidly, it is important to assess the relative merits of OMCs' massive recent investment drive. While downstream capacity, from

Page | 38 refining through to retail, needs to keep pace with rapidly growing Indian (and to a lesser extent, regional) product demand, is this demand not better (and more efficiently) met through private-sector investment?

Clearly, the Gol has decided that putting in place sufficient domestic downstream capacity is too important to leave to uncontrolled market forces and the private sector. It is unlikely that this policy will lead to greatly poorer outcomes in terms of cost effectiveness, service, reliability and product delivery for India's consumers. OMCs have proven themselves to be largely dependable and innovative operators, and there remains a great deal of beneficial competition between each of the OMCs, as well as with private-sector firms. Again, the issue is largely a fiscal one: is the Gol willing to continue to support OMCs' necessarily large capital expenditures at the current level given innumerable competing developmental priorities and the current fragility of its budget? If not, policy makers will need to be certain that the private sector is willing and able to fill the investment "gap" created by decreasing government support for OMCs. In this case, the Gol will need to make concerted efforts to ensure the downstream business environment is increasingly conducive to large-scale private investment. These issues will be examined in Chapter 6.

Is OMC investment "crowding out" private-sector downstream investment in India? The answer, to some extent, is yes. Large and fast-growing OMC refinery capacity inevitably diminishes the potential market share for private corporations. Currently, however, the private sector is limited in the operations it can profitably conduct in India's downstream sector, given product price controls. Further, proportionally greater involvement in India's downstream sector by private firms is not likely to considerably affect the level of product delivery or service quality provided to Indian consumers.

In fact, private-sector refiners are often operating in a slightly different market segment to OMCs. OMCs are above all tasked with, and focussed on, serving India's domestic market. While the rapidly growing Indian liquid fuels market is an attractive commercial prospect, privatesector refineries have been established largely to produce exports destined for North Atlantic, Middle East and East-Asian export markets, where refinery investment has lagged demand growth, and structural product market tightness persists. Given these two largely separate business models and markets, expanding publicly-owned and domestically focussed refinery capacity will not altogether "crowd out" private-sector investment in India's downstream sector. As will be examined in the following chapter, due to a number of forces, private-sector refinery investment in India has been very strong in recent years and is forecast to remain robust in the medium term. In fact, Chapter 5 argues that as a result of remarkably strong investment by private-sector refiners as well as OMCs, in spite of obstructive pricing policy, India is likely to emerge as Asia's largest refined product exporter by 2012. 


\section{Chapter 5. Will India emerge as a major global refined product exporting hub?}

As set out in its $11^{\text {th }}$ Five-Year Plan, the Gol seeks to establish India as a global refined product exporting hub, both by instructing OMCs to take a more outward-oriented operating stance, and by encouraging private-sector refiners to invest in export-oriented refining capacity. This chapter will examine the extent to which India is likely to realise this internationally-significant policy and commercial goal in the medium-term.

The measure of India's refined product export capacity over time will be the build-up of excess refinery capacity over domestic demand. ${ }^{43}$ In fact, India's actual refined product export volumes are likely to be larger than the aggregate of excess capacity. OMCs look to first supply the Indian market, and then to export the balance of refined product produced. Private-sector refiners, however, have no operational directive to first supply domestic markets. They will look to produce a product slate which optimises total refining margins from period-to-period, and will sell to customers, irrespective of location, to allow this. Export markets are therefore not a "balance" option for private-sector refiners, but integral to their business model. There is thus the possibility of a situation in India of large exports of refined products in parallel with product imports to satisfy domestic demand. In the context of sectoral expansion to facilitate greater export potential, however, excess refinery capacity is nevertheless a valid measure of India's growing exporting potential.

The emergence of India as a global refined product exporting hub is likely to have significant implications for regional product markets, extending the depth of product markets in the Middle East and South-east Asia in particular. It is also likely to have competitive effects for established Asian refinery centres such as Japan, South Korea and Singapore, and even as far afield as the United States Gulf Coast, and North-Western Europe. ${ }^{44}$ Growing exports of refined product from India have the potential to add to the energy security of countries in the Middle East and Asia-Pacific that are increasingly reliant on refined product imports, such as Iran, Saudi Arabia, Vietnam, Indonesia and Australia. But, at the same time, they threaten to undermine competing (and often ageing) refineries in countries such as Japan, South Korea and Australia.

This chapter looks primarily at the period to 2012, when the last of the current spate of refinery capacity additions in India will be completed. No large greenfield or brownfield refinery additions have been firmly proposed for start-up after 2012, given all projects finish to current project timelines. Several smaller expansion and upgrading projects are planned by RIL and each of India's OMCs to 2015. Given the lack of known firm investment plans, it is unlikely there would be any major capacity additions in India between 2012 and 2015, despite the breakneck speed in which Indian projects are completed. Further, it is difficult to anticipate policy settings for the period after 2012 - which impact directly on investment - until the release of the

\footnotetext{
${ }^{43}$ Of course, in order for India to emerge as a truly world-significant refining hub, it will be necessary to establish (through a combination of private- and public-sector investment) the key institutions and infrastructure required for the workings of such a hub (road, freight infrastructure, ports, mass-handling facilities, pipelines, etc). Description of investment dynamics in these fields is beyond the scope of this report - it is assumed that investment in infrastructure and institutions lags behind refinery capacity investments.

${ }^{44}$ See FACTS (2009), Asia-Pacific Oil Product Balances, Oil Databook II p. 2.
} 
$12^{\text {th }}$ Five-Year Plan in 2011. Analysis below therefore confines itself to the medium-term focussing on the period to 2012, but also looking ahead to 2015. There is more data available on regional refinery capacity addition post-2012. For example, significant refining capacity (over $2 \mathrm{mb} / \mathrm{d}$ ) is scheduled to come on-line across the Middle East after 2014, particularly in Saudi Arabia, Kuwait and Iran.

Page | 40

\section{Demand growth in Asia-Pacific and the Middle East}

The commercial and policy impetus to establish India as major refined product exporter above all stems from strong medium- and long-term demand growth forecast in the Asia-Pacific and Middle East regions, and the gradual establishment of Asia as the key emerging pole of international liquid fuel demand. According to the IEA's 2008 World Energy Outlook, close to $85 \%$ incremental oil demand to 2030 will come from Asia-Pacific and the Middle East. ${ }^{45}$ While the global recession slowed the pace of economic growth, non-OECD Asia and the Middle East are still expected to post strongly positive growth in 2009-10 and return to high levels of growth after 2011. In the five years to 2014, petroleum product demand growth in Asia (excluding China, South Korea and Japan) and the Middle East is forecast to rise by about $4 \%$ per annum. China's product demand is expected to grow by an average of $4.5 \%$ per annum to 2014 . As recognised by both Indian policy makers and by private industry, there is thus significant opportunity to leverage India's commercial and geographic comparative advantages to establish refinery operations that supply a share of this rapid expansion in regional liquid fuels demand.

Chart 11. Strong Asian product demand growth

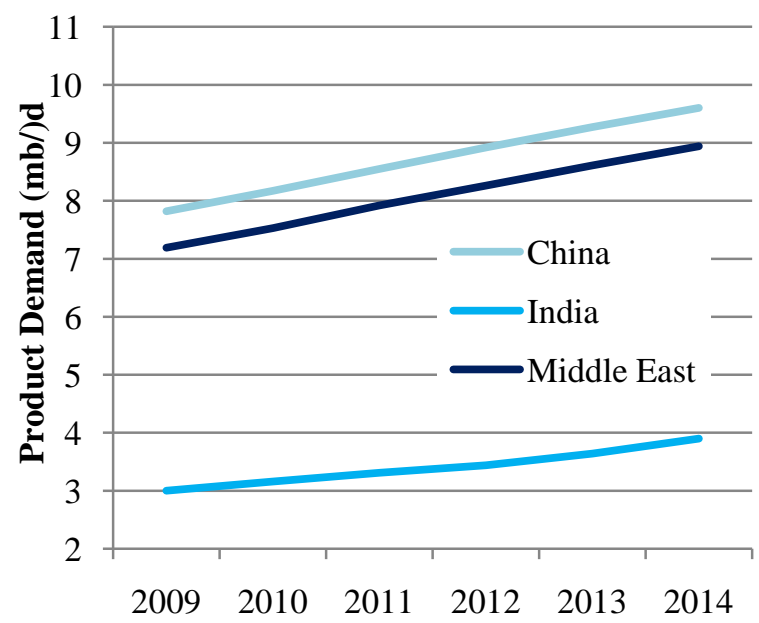

Source: IEA Medium-Term Oil Market Report (MTOMR).

It is not only Asian markets that Indian refined product exports are intended to penetrate. RIL, for example, planned to send up to $30 \%$ of total export spot cargoes (about $75 \%$ of exports) from Jamnagar II to the United States before the onset of the current global recession, and leased significant product storage space in New York Harbour in 2008. In order to supply North Atlantic markets (where no greenfield refinery has been constructed in 25 years), RIL and Essar's

$\overline{45}$ IEA (2008), World Energy Outlook, pp. 62-65. 
existing refineries are configured to produce EuroV quality fuels. ${ }^{46}$ In the same way, all greenfield OMC refining capacity is required by the Gol to meet the most stringent global fuel quality standards so that product can be readily exported if necessary to the United States, Europe, Japan and Australia. Indeed, the large size, complexity and modernity of India's new refining complexes put them at significant advantage to the smaller and older refineries in the established markets of Europe and North America. According to the IEA's 2009 Medium-Term Oil Market Report, for example, more than $2 \mathrm{mb} / \mathrm{d}$ of refining capacity in Europe is under threat of permanent closure due to competition from new, cheap, large-scale and complex refining projects in developing Asia and the Middle East. ${ }^{47}$

\section{Medium-term refinery capacity addition in India}

Put simply, India will have undergone little less than a revolution in domestic refinery capacity addition, sophistication, orientation and global importance in the years of the $11^{\text {th }}$ Five-Year Plan. Charts 12 and 13 depict the brownfield and greenfield refinery additions occurring in India to 2012 , some of which were reviewed in the previous chapter. From a current refining base of $3.54 \mathrm{mb} / \mathrm{d}$, India will increase refining capacity to close to $5 \mathrm{mb} / \mathrm{d}$ by around 2012, a huge increase of over $40 \%$ in three years. OMCs will collectively add $600000 \mathrm{bbl} / \mathrm{d}$ in greenfield refinery investment, spread over three different projects. This, for example, is greater than the entire accumulated refining capacity of Malaysia. Private-sector firms will add just over $500000 \mathrm{bbl} / \mathrm{d}$ in greenfield investment, led by the $400000 \mathrm{bbl} / \mathrm{d}$ Phase II of Essar's Vadinar refinery (and assuming this project goes ahead). Downstream companies - both private and publicly-owned - will also add close to $350000 \mathrm{bbl} / \mathrm{d}$ in brownfield expansion to India's existing refineries. Together, this is a huge medium-term increase in capacity.

Private-sector refiners, in particular, have invested heavily in India in recent times. From the commissioning of Jamnagar II in late-2008 to the scheduled commissioning of Essar's Vadinar II in 2012, private-sector refiners will have added around $1.2 \mathrm{mb} / \mathrm{d}$ of new refining capacity (not including Jamnagar I). This is close to the size of the entire current refining capacity of Singapore (that is, $1.27 \mathrm{mb} / \mathrm{d}$ ), the established refining powerhouse of South-East Asia. In Chapter 4 it was argued that the level of OMCs investment in Indian refining has not been significantly affected by the current system of petroleum product pricing that burdens these firms with large retail under-recoveries. In the same way, it seems that private-sector investment has not been significantly affected by the distortionary system of product price regulation. Indeed, by 2012, India will operate private refining capacity of over $2 \mathrm{mb} / \mathrm{d}$. This continued robust investment despite a sub-optimal national pricing framework may be explained by two key factors.

- The role of OMCs: As stressed before, OMCs absorb the retail losses within the current system of pricing. When supplying the growing Indian market, private-sector refiners are able to sell to OMCs at market-based refinery-gate prices, without carrying any underrecovery risk. It is also important to note that price restrictions only apply on four products (albeit those that make up a large majority of domestic petroleum product consumption). Private-sector refiners are therefore able to market industrial fuels, lubes, jet fuel, etc., at market rates without restriction.

\footnotetext{
${ }^{46}$ Emerging national fuel standards in the United States are modelled on California's strict fuel standards, which themselves are based on Euro-standards.

${ }^{47}$ IEA(2009), Medium-term Oil Market Report, June, p. 85.
} 
- India as an export base: Putting aside the regulatory complexities of domestic product markets, private-sector refiners have considerable incentive to establish operations in India simply as a base for international product exports. ${ }^{48}$ Some of these comparative advantages were already discussed in Chapter 3. India immediately straddles the world's major crude producing countries in the Middle East, to its west, and the key pole of global petroleum product demand growth - East and South-East Asia - to its east. Its proximity to the Middle East also gives Indian refiners access to another rapidly growing market for petroleum products. Perhaps more significantly, Indian production, construction and unit labour costs are far lower than in the developed world, while skilled labour and high-quality capital (in terms of both access to financial markets and high-tech capital machinery) are relatively abundant.

Chart 12. Brownfield refining capacity addition to 2012

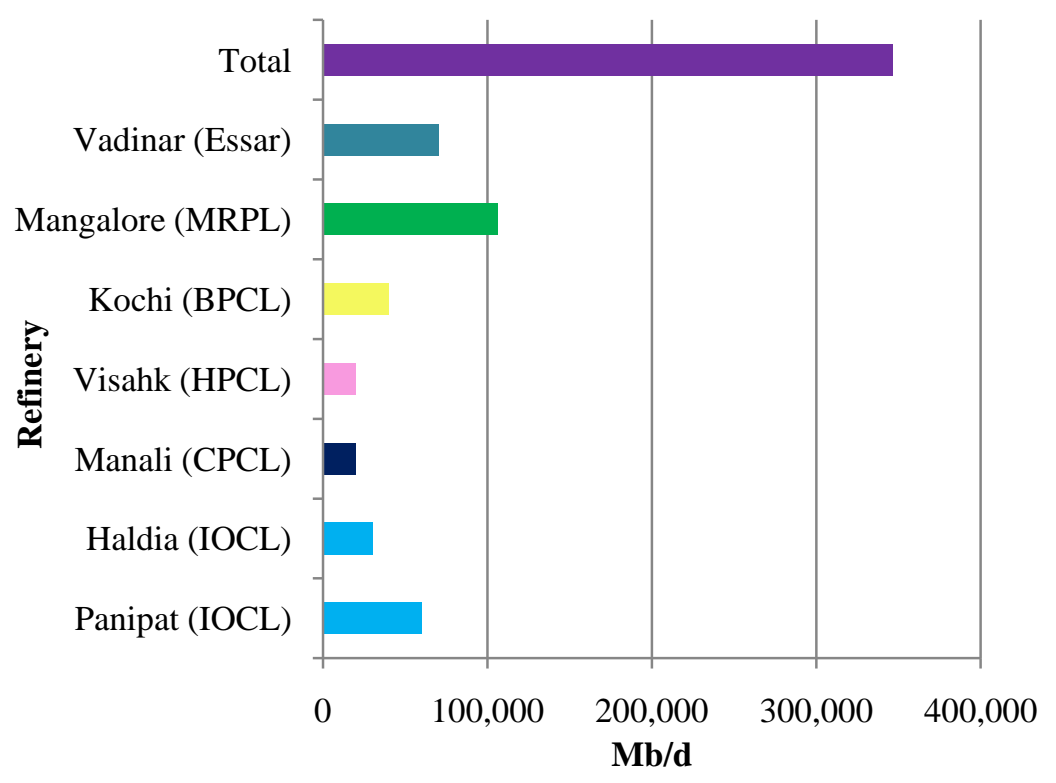

Source: Ministry of Petroleum and Natural Gas (MPNG).

Mukesh Ambani, Chairman of RIL, famously boasted that Jamnagar I was built "with double the men, at half the cost and in half the time" typically expected for large-scale refinery projects. ${ }^{49}$ Jamnagar II was completed in 36 months from concept to commissioning - a global benchmark for a refinery of its scale and complexity. IOCL's $300000 \mathrm{bbl} / \mathrm{d}$ greenfield refinery project currently under construction, for example, is employing a temporary construction workforce of over 100000 labourers - a mobilisation that would likely be impossible outside of a handful of nations such as India (and e.g., China and Indonesia). After the approval to construct Jamnagar II, Mr. Jeet Bindra, Chevron Texaco's Head of Global Refining, admitted that establishing refineries in developed countries was quickly becoming unviable when matched

\footnotetext{
${ }^{48}$ In fact, several private-sector export-only refineries have been planned in the past, although none have been successfully put in place as yet. See the discussion of the proposed Total S.A. refinery project below. ${ }^{49}$ Quoted in Wall Street Journal, "Giant Oil Refinery in India Shows Forces Roiling Industry", 29/08/2006.
} 
against huge Asian complexes such as Jamnagar. ${ }^{50}$ Instead of looking to expand capacity in the United States, therefore, Chevron took a small (5\%) stake in the Jamnagar complex, with plans to increasingly rely on product imports to the United States, rather than domestic refining. Despite the current regulatory conditions, there are therefore compelling, cost, commercial and competitive reasons for private-sector firms to look to establish export-oriented refining operations in India.

Chart 13. Greenfield refinery projects to 2012

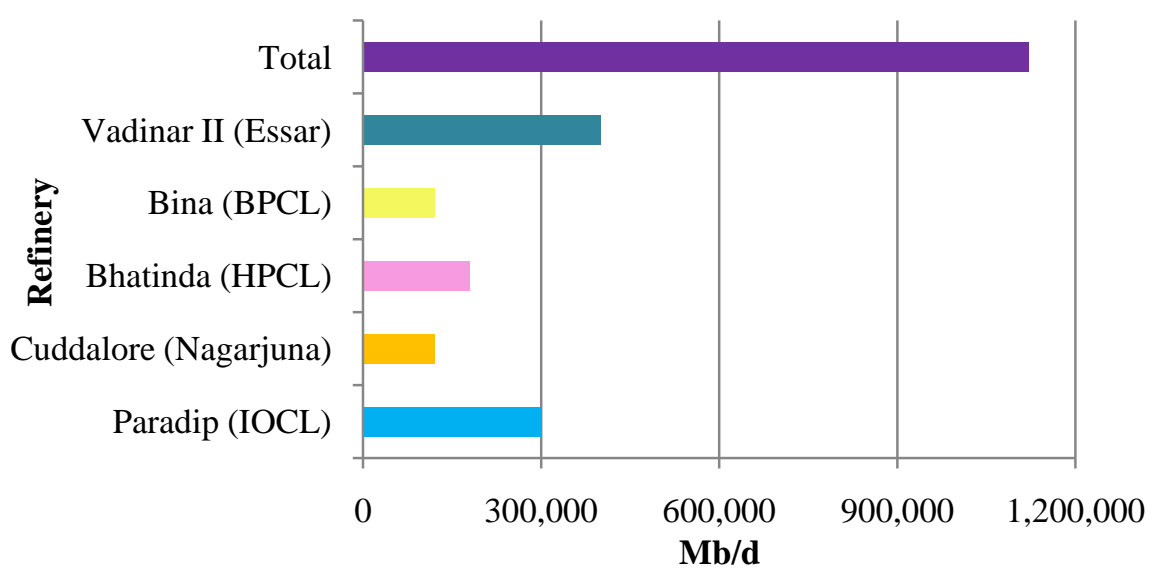

Source: Ministry of Petroleum and Natural Gas (MPNG).

\section{International oil companies and the global recession}

\section{Where are the "Majors"?}

A key feature of India's downstream sector currently is the absence of refinery operations and investment by International Oil Companies (IOCs). ${ }^{51}$ Each of the Majors has marketing and distribution operations for industrial fuels and lubes in India, and Shell has a permit to establish retail outlets (as the only foreign-owned company with this right). ${ }^{52}$ However, none of the Majors, or any other foreign-owned petroleum corporation, have refining operations in India. Only Chevron has (small) equity holdings in existing refineries, as noted above. IOCs have shown considerable interest in Indian refinery projects in the recent past, however, in all cases they have pulled their interest at critical stages.

In mid-September 2009, Total S.A. pulled out of a planned joint venture $300000 \mathrm{bbl} / \mathrm{d}$ "exportsonly" refinery project in Visakh in Andhra Pradesh headed by HPCL and including the Mittal

\footnotetext{
${ }^{50}$ See article as above, Wall Street Journal, 29/08/2006.

${ }^{51}$ It should be noted that the lack of IOCs presence in refining sectors is common across the Asia-Pacific region, and not just India. According to FACTS Energy, 94\% of refinery investment in developing Asia to 2012 will be undertaken by "local companies" (e.g., RIL, Essar, etc.) or National Oil Companies. The implication is that IOCs may simply be more comfortable concentrating large-scale, risky investments in mature markets where legal and commercial frameworks are better established.

52 The Majors are: Exxon-Mobil, Shell, BP, Chevron-Texaco, Conoco-Phillips and Total.
} 
Group, after Mittal put on hold its participation in November 2008. Land had been purchased by $\mathrm{HPCL}$ to house the refinery. Total pointed to the recent collapse in global petroleum product demand as the key reason for its decision. Before this, both Exxon and BP had expressed interest in joint partnerships with HPCL to establish the Bhatinda refinery in Punjab State (which is now going ahead as a joint-venture between Mittal Group and HPCL). In 2000, Exxon-Mobil Page | 44 pulled out of an agreed partnership with HPCL to jointly construct the $180000 \mathrm{bbl} / \mathrm{d}$ refinery. Later, in 2005, BP signed an MOU with HPCL agreeing to 50:50 equity partnership in the establishment of the project, however BP pulled out less than six months later. Shell, on the other hand, has not expressed interest at all in any particular refining project. Shell representatives have reportedly stated recently that, "while product marketing is a current priority, there is no reason to say that we will not be looking at a refining asset". It is not expected, however, that Shell will consider refining projects in India before 2015.

It is quite difficult to pinpoint the reason for IOCs' tentativeness in entering the Indian refining market, indeed in entering Asia-Pacific markets in general. In the case of India, it may be partly the result of a case of First-Mover Advantage at play in the private-sector refining sector. Aside from Total's Visakh project, the explanation that IOCs have each given for the breakdown, and lack of, refining project plans is the existence and rapid expansion of RIL's Jamnagar complex. In a single ambitious move - the building of Jamnagar I - RIL effectively saturated the exportoriented refining market in India. RIL then built on its extensive physical infrastructure and maturing international trade and distribution networks to further dominate the private-sector refining industry in India with the development of Jamnagar II. RIL's large initial investments have to this point crowded out refinery investments by IOCs, who will naturally weigh up investment options across a number of geographic locations. This is not to suggest that this situation will remain permanent. With the slowing of RIL's own capacity additions in the medium-term and the further growth of world, Asian and Indian product markets over time, the commercial and competitive drivers discussed above that make India an attractive destination for refinery investment are likely to be re-asserted. The emergence of Essar (albeit currently on a smaller scale) as a competing operator with RIL on India's West Coast is an indication of the beginning of this process.

IOCs' unwillingness to invest in refining in India may also be partly explained by India's system of product pricing. It has been argued in both this chapter and that preceding it that neither private-sector nor OMC refining investment has been significantly affected by India's current system of price controls. This is undisputedly the case. Both private-sector and public-sector companies have invested heavily in additional refining capacity recently. However, this assessment is better confined to local private-sector firms. While the operations of a "local petroleum company" such as RIL are concentrated overwhelmingly in its home country (in which it is likely to have highly embedded, well-established commercial associations and supplychain linkages), IOCs have operations across the globe, and, as mentioned, will weigh up investment options across a number of geographic locations. When choosing a destination for costly and highly capital intensive refining investments, IOCs are naturally likely to avoid those locations, such as India, where they are currently unable to profitably enter retail markets and roll-out global corporate brands to consumers. While local private-sector refiners very profitably supply India's domestic markets via sales to OMCs, IOCs will likely demand deeper market penetration and clear brand access from a destination for large-scale, risky investment, despite the size of India's domestic market. 


\section{Impacts of the global recession}

As with the rest of Asia, the global economic downturn since 2008 has had relatively little impact on refining capacity projects in India. The fact that investment is based on expectation of long-term growth means that pre-financed refinery developments are unlikely to be disrupted by short-term macroeconomic fluctuations, no matter how severe. All planned investments are expected to go ahead approximately according to original timeframes, except for Essar's construction of its $400000 \mathrm{bbl} / \mathrm{d}$ Vadinar II refinery in Gujarat, which has a revised start-up date of late-2012, compared to late-2010. Essar has blamed a tighter financing environment and uncertainties over the pace of global product demand recovery for the delay. The current global economic slowdown has, however, affected a very small number of early-stage refinery investment proposals, such as the proposed joint venture refinery project between Total S.A., HPCL and Mittal Group. In reality, the global recession is only one cause of the breakdown of these fledgling proposals, which is also the result of long-term concerns of emerging structural excess capacity in Asia, as well as the planned removal of several of the Gol's tax holidays for refineries commissioned after 2012.

\section{Implications of India's growing excess capacity}

With forecasted total domestic refining capacity of $4.96 \mathrm{mb} / \mathrm{d}$ by 2012, India will become the world's fourth largest refining centre, after the United States, China and Japan. Although expected to grow strongly, Indian product demand to 2012 will grow far less rapidly than additions to its domestic refinery capacity. India currently consumes petroleum products at a rate of just over $3 \mathrm{mb} / \mathrm{d}$, growing briskly at slightly more than $4 \%$ per annum to $3.44 \mathrm{mb} / \mathrm{d}$ in 2012. By 2012, therefore, domestic refining capacity will exceed product demand by over $1.5 \mathrm{mb} / \mathrm{d}$. Assuming refinery capacity utilisation of slightly below $100 \%$, by 2012 India will be in a position to export approximately $1.4 \mathrm{mb} / \mathrm{d}$ of refined product to global markets. ${ }^{53}$ This would make India Asia's largest refined product exporter, surpassing Singapore - which is expected to export $1.2 \mathrm{mb} / \mathrm{d}$. As sought by its 11th Five-Year Plan, therefore, India seems likely to become Asia's preeminent refined product exporter in the short-to-medium-term, and one of the world's largest petroleum product exporters.

With the establishment of the world-leading Jamnagar complex and the imminent start-up of close to $1.2 \mathrm{mb} / \mathrm{d}$ of highly complex greenfield refinery capacity, India looks likely, in particular, to dominate Asian exports of highest quality products such as high-octane gasoline, alkylate, ultra-low sulphur diesel and petcoke. The emergence of this large-scale and complex refinery capacity in India will greatly increase the resilience of regional supply-chains for these high-end industrial and auto fuels.

Putting aside regional industry cycles that fluctuate between scarce and excess capacity, the establishment of India, along with Singapore, as a consistent large-scale exporter of refined products in Asia in all cyclical conditions and from period-to-period will substantially deepen and strengthen refined product trade flows in the "Indian Ocean rim" (stretching from Africa and the Middle East in the west, to South-East Asia, East Asia and Australia in the east). This will be especially the case for diesel, jet fuel, gasoline, and, as mentioned, complex, high-end product trade flows and supply chains. Currently, Asia-Pacific trade in refined product is

\footnotetext{
${ }^{53}$ This calculation is supported by a range of sources, including FACTS (2009), Asia-Pacific Oil Product Balances, Oil Databook III, April.
} 
relatively small compared to total product consumption. In 2008 Asia-Pacific countries together imported around $5 \mathrm{mb} / \mathrm{d}$ of refined product, out of total consumption of over $24 \mathrm{mb} / \mathrm{d}$. This is compared with Europe, for example, where close to $40 \%$ of total product demand is sourced from outside the country in which it is consumed. Asia-Pacific countries are therefore highly reliant on domestic refining to meet demand, and trade linkages in refined product are weak and under-established. This situation contributes significantly to limited flexibility in product supply chains, making both short-term product supply disruptions and long-term adjustment to increasing import dependence much more problematic.

Chart 14. Indian refining capacity vs domestic demand, 2009-12

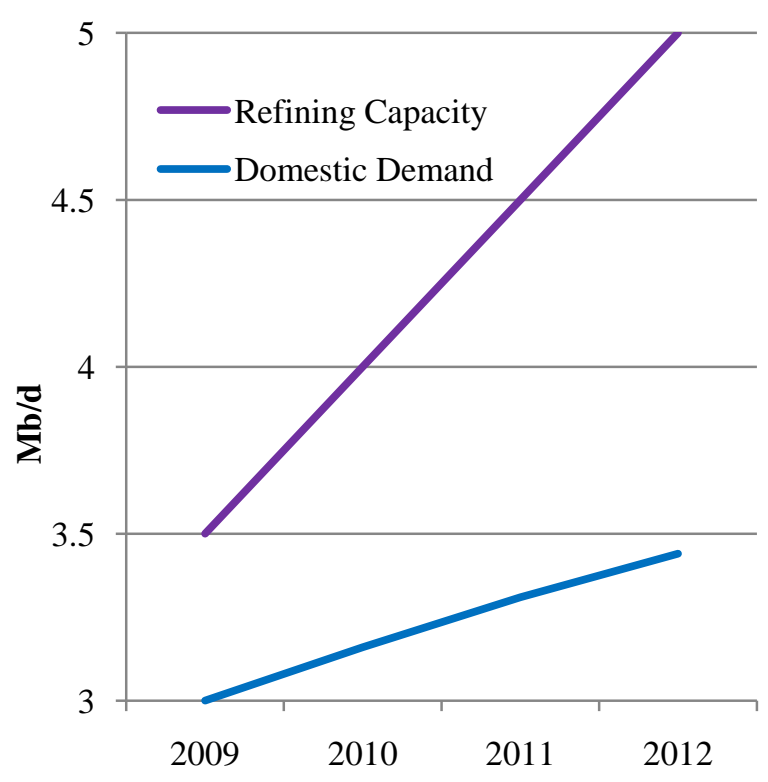

Source: MPNG and MTOMR.

The addition to 2012 of over $1 \mathrm{mb} / \mathrm{d}$ of traded refined product cargoes in Asia emanating from India (between April and July 2009 about 75\% of product exported from Sikka port at Jamnagar was destined for the Indian Ocean rim) will significantly increase the depth of product flows in the Indian Ocean and strongly contribute to growing flexibility in regional supply chains. This additional $1 \mathrm{mb} / \mathrm{d}$ of traded product is close to $20 \%$ of Asia-Pacific countries' total expected imports of refined product (i.e., $6 \mathrm{mb} / \mathrm{d}$ ) by 2012. It is difficult to predict exactly to where India's growing petroleum product exports will be destined once demand in North Atlantic markets recovers. However, even if exports are somewhat diverted to meet demand in Europe and the United States, this will displace Western markets' demand for refined product from traditional exporters in Asia such as Singapore, Japan and South Korea, freeing-up significant export volumes for trade centred within Asia.

The recent deepening of Indian Ocean rim refined product markets, significantly led by Indian export-oriented product volumes, is one of the most important developments in global petroleum product markets to occur in recent years, and a pattern that is likely to accelerate over the next decade. ${ }^{54}$ It implies a fundamentally changing configuration of global refining, in

\footnotetext{
${ }^{54}$ See, for example, OPEC (2008), World Oil Outlook; FACTS Energy (2009), Asia Pacific Oil Product Balances: Databook III; FACTS Energy (2009), Asia Pacific Refinery Configuration and Construction: Databook II; and EIA (2009), International Energy Outlook.
} 
which, increasingly, refined product is mass-produced in what may be termed "South Asia" - a region broadly encompassing the Middle East, India and South-East Asia - and then exported along increasingly resilient trade routes and robust supply chains to both mature economies and smaller emerging markets that look to these producer hubs to supply incremental product demand growth over time. This is a case of comparative advantage asserting itself in increasingly open international energy markets. For slow-growing mature markets (such as in Europe, the United States and Australia), it is increasingly unviable to undertake extremely costly, lengthy, labour-intensive, and regulation-intensive refinery investments (and even upgrades) to meet incremental demand. This is well-understood in South Asian countries - the huge refinery complexes of India, Singapore and the Middle East are designed largely to fill this refinery investment gap in the West (where, as mentioned, no greenfield refinery has been built since the mid-1980s).

Chart 15. Forecast Asia-Pacific refined product exports, 2012

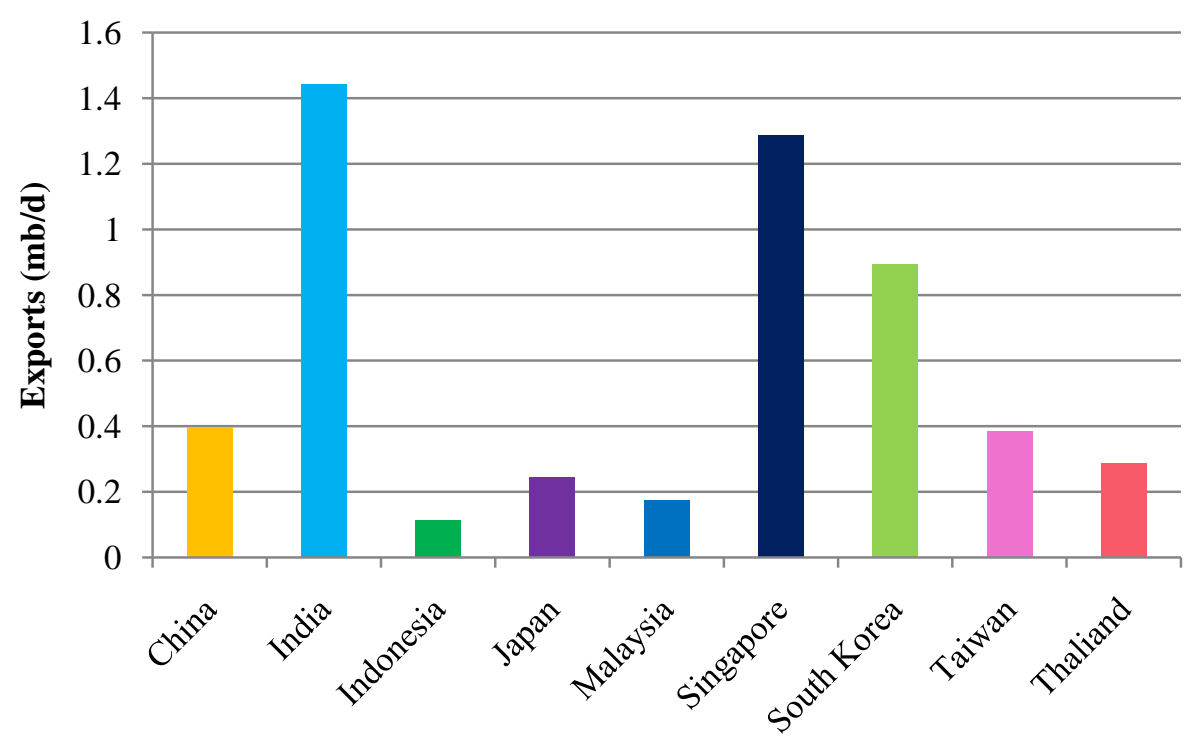

Source: FACTS Global Energy.

Increasingly robust refined product supply chains in the Indian Ocean rim will naturally develop from market interactions that match growing product volumes from producers such as India, with refined product deficits in established markets (especially as economies recover from recession). Policy makers, however, should formulate policy tools that encourage domestic downstream industries to embrace and engage with the changing geographic configuration of refinery production in order to ensure national liquid fuels supply chains are best integrated into evolving global patterns of liquid fuels trade and production.

\section{Risks and challenges}

\section{Emerging regional excess capacity}

There are several risks to the continued perpetuation of India's status as the largest exporter of petroleum products in Asia that need to be overcome in the next decade. The most pressing of 
these is the almost unprecedented emergence of structural excess refining capacity across the Asia-Pacific region. Strong India refinery capacity addition has been mirrored, to a large extent, across the region. After adding close to $600000 \mathrm{bbl} / \mathrm{d}$ in 2008, China is expected to add another $800000 \mathrm{bbl} / \mathrm{d}$ of new refining capacity in 2009 - a yearly figure larger than India's capacity additions in this year, despite the start-up of Jamnagar II. At the same time, both Japan and Page 48 South Korea face structurally declining refined product demand combined with large domestic refinery industries, and therefore growing domestic excess capacity. In the context of very weak local, regional and global demand, smaller refiners such as Thailand and Taiwan are also likely to face increasing surplus capacity from 2009. Regional excess refining capacity is consequently expected to increase sharply from $1.4 \mathrm{mb} / \mathrm{d}$ in 2008 to $3.9 \mathrm{mb} / \mathrm{d}$ in 2010 . Refiners across the region will therefore be looking to the same export markets to absorb their surpluses. ${ }^{55}$ Alternatively, refineries will be forced to significantly cut runs, or to consider sectoral consolidation (as is likely in Japan and, to a lesser extent, South Korea).

Unfortunately for refiners needing to rapidly increase exports, global refined product demand is still reeling from the worst negative demand shock to affect international oil markets since the early-1980s. The capacity for global markets to absorb regional excess capacity is therefore strictly limited. ${ }^{56}$ The Asian refining industry is thus bracing itself for a painful period of significant market oversupply and historically-low refining margins (and, as a result, lower crude throughput and sectoral structural adjustment). As an indication of the likely extent of refining margin depression, when regional excess refining capacity reached $1.1 \mathrm{mb} / \mathrm{d}$ (significantly less than that forecast for the period 2009-12), the Singapore gross cracking margin remained very low, at USD $0.75 / \mathrm{bbl} .{ }^{57}$ Asian refiners, in general, can therefore expect to continue the current period of low margins, weak crude runs, commercial hardship and industry rationalisation.

Indian refiners are likely to fare significantly better than competitor refineries in other Asian countries. Firstly, the large scale and world-leading complexity of India's new greenfield refineries mean marginal costs of production are significantly less than older, less complex facilities, thereby increasing refining margins. Secondly, India's new refinery capacity is equipped to process heavier and cheaper crude grades, again putting upward pressure on refining margins by lowering input costs. Finally, as mentioned, Indian refineries are configured to produce complex, high-end products which will retail in international markets for somewhat of a premium. This too will support refining margins. The ability of the Indian refinery sector to avoid the worst consequences of regional excess capacity and to maintain market share as a result of unique, clean and high-end product slates will at the same time directly worsen the difficulties of refiners in Japan, South Korea and South-East Asia during the expected period of cyclical over-capacity. As FACTS Energy puts it, "with the emergence of sophisticated Indian operations, [the established refining centres] will find they are living in a world very different to the one they are accustomed to. From late-2009, India's establishment as a very low-cost product export hub will bring intense competitive forces to bear on less sophisticated export-

\footnotetext{
${ }^{55}$ While the Middle East currently faces a deficit of key transport fuels, large-scale refinery projects scheduled to come online after 2014 will more than absorb this deficit, further increasing competitive pressures in Indian Ocean rim product markets.

${ }^{56}$ The extent of the absorption of rapidly growing excess refinery capacity in Asia will depend to a large extent on product demand in China. If demand growth is weak and does not keep pace with China's domestic refinery capacity addition, Chinese refiners, too, will look to international markets to absorb surpluses, adding to oversupplied markets. On the other hand, if China's demand grows faster than refinery capacity, China will look to regional markets to meet demand, somewhat dampening the extent of the expected product glut.

${ }^{57}$ FACTS Energy (2009), Asia Pacific Oil Product Balances: Databook III, April, pp. 1-4.
} 
oriented refineries in Asia, particularly in Singapore, adding to the problems associated with the financial crisis". ${ }^{58}$

Despite the significant factors in their favour, however, Indian private-sector refiners (and to a lesser extent OMCs) will not be able to completely avoid the combined commercial impact of market glut and shocked global demand. Like the rest of Asia's refiners, although to a lesser extent, in the short-to-medium-term India's refiners will be forced to endure an undefined period of commercial difficulty.

\section{Falling refinery investment in India}

Emerging evidence of developing regional excess capacity in the short-to-medium-term has rapidly halted the surge in refinery capacity investment in India. After 2012, and the projected completion of Essar's large Vadinar II refinery project, both OMCs and private-sector firms have a lack of firm plans for significant refining capacity expansions. Recognising the potential for a regional refining capacity glut in the future, the Gol has reduced refinery capacity addition as key commercial priority, removing its income tax holiday on refinery projects commissioned after 2012. Clearly, Indian refiners are preparing for a difficult period of weak average refining margins and lower crude runs, and choosing to consolidate operations rather than to expand.

The expected plateau in Indian refinery investment has significant implications for India's status as a major global liquid fuels hub. In contrast to slow refinery capacity addition after 2012, domestic demand in India is expected to experience strong, robust growth, with the last vestiges of the global recession likely to have disappeared. As Chart 16 illustrates, there will therefore certainly be a reduction in India's excess refinery capacity. It is noteworthy to compare Chart 16, depicting Indian product demand versus refinery capacity addition to 2012, with Chart 14 above. The reduction in excess capacity will inevitably result in lower product export volumes emanating from India. Indeed, with strong domestic demand and sluggish capacity addition, by 2015 India is no longer forecast to be the largest refined product exporter in Asia, with exports falling to just over $1.2 \mathrm{mb} / \mathrm{d} .{ }^{59}$ Singapore, on the other hand, is expected to export around $1.4 \mathrm{mb} / \mathrm{d}$ in 2016.

In the face of strongly growing domestic demand, for India to truly cement its position as a major international petroleum product exporter, Indian refiners - both public and private - will have to maintain fairly high degrees of investment to preserve levels of export-oriented refining capacity. There are, however, certain financial barriers to the achievement of this sustained level of refinery investment. Private-sector refiners, on the one hand, are entering a period of uncertainty, instability and cyclical excess capacity. They are unlikely to be willing or able to continue large-scale capacity expansion. To the extent that OMCs' revenues remain dependent on government revenue, the Gol faces pressure over the medium-term to consolidate the central budget, and reign in spending. Alternatively, as OMCs begin to operate in a more open and commercialised fashion with the liberalisation of product markets over time, they too will increasingly face the commercial pressures of the refining industry "down-cycle". The Gol will

\footnotetext{
${ }^{58}$ FACTS Energy (2009), Asia Pacific Refinery Configuration and Construction: Oil Databook II, April, pp. 4-5.

${ }^{59}$ As noted above, India's export volumes are likely to be larger than the aggregate of domestic excess capacity, as private-sector refiners look to supply global product markets at the same rate as domestic ones. Nevertheless, the reduction in excess capacity will inevitably translate into smaller export volumes over time, as demonstrated by the forecast export figures noted.
} 
therefore need to balance product pricing liberalisation with a commitment to upholding investment plans by OMCs that are aligned with the downstream sector policy goal of maintaining India as a major global refined product exporter.

Chart 16. Indian refining capacity vs domestic demand, 2012-15

Page | 50

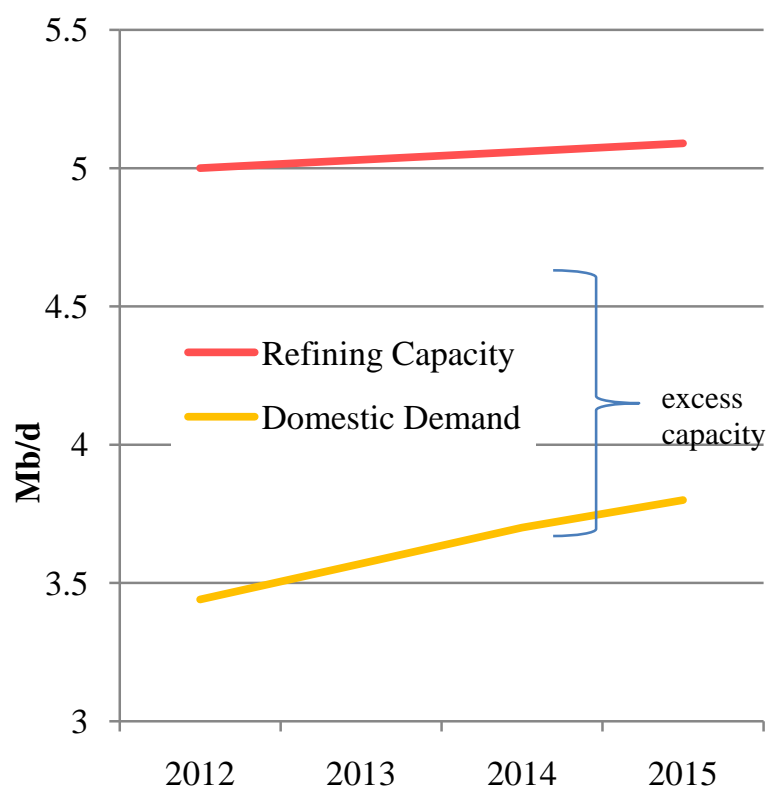

Source: MPNG and MTOMR.

\section{Evolving from exporter to genuine hub}

Singapore's success within international energy markets has been its ability to establish itself as not merely a large refined product exporter, but as a truly world-significant liquid fuels trading hub and centre of commerce. Singapore has become the world's preeminent liquid fuels trading centre "east of Suez". It has put in place extensive and state-of-the-art shipping, handling and port facilities, world-class institutions of trade and commerce, and one of the world's largest local fuel storage capacities. In doing so it has attracted a large service industry in liquid fuels (and shipping) trading, financing, consulting, management and regulation that services this dynamic sector. A significant proportion of the economic "value-added" of the liquid fuels sector comes from the associated service industries, rather than the actual physical trade of liquid fuels.

India, in the short-term at least, will become Asia's largest exporter of refined product and, with Singapore, one of the two key centres for traded refined product in Asia. However, it still has significant progress to make in establishing itself as a genuine, well-functioning liquid fuels trading hub, with associated and lucrative service industries. As India has, to some extent, completed the difficult task of establishing the necessary physical refining capacity for the moment, the transformation to trading hub is primarily an exercise in concerted industry policy and institution building. In particular, the Gol needs to establish the institutions of finance, commerce and trade within the sector. The city of Mumbai is India's rapidly growing financial centre and the obvious geographic locus of India's export-oriented refined product sector (with RIL and Essar's huge facilities located to the north at Jamnagar, Mangalore refinery to the south, 
and close to $400000 \mathrm{bbl} / \mathrm{d}$ of refinery capacity within the city itself). There is considerable potential for Mumbai to develop into a key global centre of liquid fuels trade, leveraging on rapidly increasing Indian product trade, and transforming India from a very large refined product producer to genuine trading hub. For this to occur, the Gol must above all establish a state-of-the-art liquid fuels trading exchange in Mumbai that facilitates rapid, inexpensive and sophisticated trade in physical fuels and fuel contracts. This is the key institutional basis for the development of multilateral trade and exchange in refined product, rather than simply one-way product exports, and a prerequisite for the development of a dynamic secondary sector servicing India's expanding export-oriented refining sector.

\section{Conclusion and key findings}

In keeping with the ambitious goals of the $11^{\text {th }}$ Five-Year Plan, India will emerge by 2012 as Asia's largest refined product exporter, and a major global producer of petroleum products. India's emerging refined product export industry - led by RIL's Jamnagar facility but also increasingly supported by new OMC refineries - is characterised by extremely large-scale, lowcost and modern plants capable of processing heavy crudes and producing complex, clean products. The addition of around $1 \mathrm{mb} / \mathrm{d}$ of traded refined product, especially high quality product, in the Indian Ocean rim will substantially strengthen liquid fuel supply chains in this region and deepen currently-underdeveloped Asian trade in refined product.

While India's refining successes are intimately related to the natural comparative advantages of the country itself, it has also been fostered by prudent policies and intervention by the Gol. From an outcomes perspective, the policy mix chosen by the Gol for the refining sector has been highly successful (albeit while coming at a tremendous fiscal cost). The government has singlemindedly pursued large-scale investment in refining capacity through OMCs by extending considerable financial support to these firms; by upholding confidence in OMCs within capital markets; and by providing OMCs the freedom to make investment decisions based on a range of non-commercial factors, as well as strictly commercial ones.

Just as importantly, the Gol has created a domestic downstream sector in which well-supported OMCs absorb the significant retail losses inherent in the current system of product market regulation - thereby creating a market-space in which private-sector refiners can profitably conduct business based not only on export sales, but on the penetration of India's fast growing domestic market. The appeal of this business model has driven the recent boom in local privatesector investment in Indian refining that has culminated, for example, in the emergence of Jamnagar in Gujarat as the world's largest refining centre - with close to $2 \mathrm{mb} / \mathrm{d}$ of privatelyowned refining capacity expected to be in place by 2012. Government policy has therefore succeeded in fostering a dynamic combination of private and public investment in refining capacity which has transformed the face of India's downstream petroleum sector in the years of the $11^{\text {th }}$ Five-Year Plan.

Despite its significant successes, in the long-term India faces several challenges to its growing status as global refining powerhouse. Current extensive investment will certainly ensure that India remains a key exporter of refined product, especially in the Asia-Pacific region. However, falling investment in refinery capacity after 2012, owing largely to growing regional excess capacity and a tighter fiscal environment, puts at risk India's emergence as truly one of the world's largest refinery centres in the long-term, especially in the context of growing domestic product demand. It is difficult to predict the exact trajectory of Indian refinery investment after 2015, when the current wave of investments will 
have ended. Certainly, investment will be much lower and more incremental in nature. To a large extent, investment dynamics post-2012 will depend on the content of the $12^{\text {th }}$ Five-Year Plan (beginning in 2012), just as the $11^{\text {th }}$ Five-Year Plan has intimately affected current investment trends. The Gol's move to abolish the tax holidays on refinery investment and construction occurring after 2012 , however, suggests that it is content with India's projected refinery "base" to 2012 and that it will take a less expansionary attitude to refinery capacity in the future.

While from an outcomes perspective the Gol's refinery sector policies have been highly successful, from a cost perspective, they have been close to disastrous. As has been described, in order for OMCs to be in a position to make large-scale refinery investments (and, secondly, in order for OMCs to be able to continue to incur under-recoveries, and thereby to create space for private-sector refiners to prosper), the Gol has been forced to make payments, in various forms, to OMCs amounting to close to USD 60 billion since 2004-05. This figure, for example, is about fifteen times greater than was IOCL's refinery investment for this same period. The combination of managed petroleum product prices and large-scale refinery investment has thus become extremely expensive for the Gol, contributing significantly to an alarming and rapid fiscal overflow since 2008 and temporary concerns of a "twin deficits" crisis.

The funding pattern that has largely underpinned India's refinery boom is therefore clearly and entirely unsustainable. Although a great deal of investment has been completed, India will need to incrementally add refinery capacity after 2012 to maintain its export potential. Given India's fiscal circumstances, and under rapidly tightening budgetary conditions, this investment should be increasingly sought commercially from the private-sector, including from IOCs. In order to promote increasing private-sector involvement in Indian refining, including foreign private-sector involvement, the Gol must begin the process of product market liberalisation, which will help to foster timely, effective investment responses to clear market signals, and work to encourage high-quality investment from private-sector refiners. In turn, liberalisation will reduce the dependence of OMCs on the Gol for working capital, allowing these companies, too, to invest in an efficient and timely fashion.

Reform to pricing policy in product markets will thus reduce the fiscal burden of the current system of unofficial subsidies on the Gol, and promote least-cost refining investment responses. Such reform also has secondary benefits. Clear price signals encourage fuel conservation and substitution. This will simultaneously reduce India's crude import costs, and, as substitution to cleaner fuels occurs, greenhouse gas emissions will be reduced as well while boosting energy security. For each of these reasons, the Gol should move in the direction of market-based reform in petrol, diesel, LPG and kerosene markets. It should do this, however, while employing effective policy tools, such as price ceilings and highly targeted subsidies that provide energy market access for poor Indians, especially in LPG and kerosene markets. Chapter 6 explores these issues of market reform in greater detail. 


\section{Chapter 6. A return to the issue of product pricing: paths toward market reform}

\section{Introduction}

This study has shown that private- and public-sector investment in India's downstream sector, especially in refinery capacity, has been sufficient to establish a dynamic domestic industry capable of meeting strongly growing Indian liquid fuels demand, and increasingly establishing India as a major global refined product exporter. While private-sector investment has been robust and decisive, a great deal of the burden of this task has naturally fallen to India's OMCs, the largest and most well-established companies in the downstream sector. OMCs remain financially crippled by the current system of product price regulation. Under current international crude market conditions, OMCs need to be consistently bailed-out by the Gol for selling product in domestic markets at managed prices. Similarly, effectively-insolvent OMCs have had to rely, directly or indirectly, on the Gol's oil bond issuance for working capital to fund India's ambitious public-sector downstream investment programme.

Between FY 2004-05 and FY 2008-09, the Gol pumped over USD 60 billion into OMCs to absorb product under-recoveries and to ensure OMCs were capable of continued rapid investment in capacity. Close to half of this total occurred in FY 2008-09. With international crude prices mostly above USD 70/bbl since mid-2009, the Gol is likely to be forced to make payments of around USD 15 billion in FY 2009-10 to OMCs to absorb under-recoveries. At the same time, India currently confronts a fiscal crisis of sorts - the acute combination of prevailing macroeconomic conditions (which have prompted falling tax revenues and rapidly increasing stimulus-related expenditure) and medium-term budgetary excess. In FY 2008-09, India's government deficit (across all levels of government and including off-budget components) more-than-doubled in nominal terms to $11.4 \%$ of GDP. Total state and Gol debt is estimated at $82 \%$ of GDP, and interest payments on government debt consume around $24 \%$ of the Gol's revenues. ${ }^{60}$

Under these conditions, massive expenditure by the Gol to fund the system of "unofficial" product subsidies is entirely unsustainable. The key issue in the domestic downstream sector stemming from India's distortionary refined product pricing regime is therefore not one of investment, incentives or corporate dynamism - which are all robust and healthy - but one of fiscal cost. Indeed, with international crude prices forecast to rise as the global economy recovers, the fiscal cost of the current system of petroleum pricing can only be expected to increase significantly over time. Given these huge costs, and in the context of innumerable competing priorities and the need for strict budgetary austerity, the Gol must move decisively in the direction of more cost-reflective pricing of petroleum products, as was the intention of the abolition of the APM in 2002. This chapter provides a brief discussion of some different policy

${ }^{60}$ Standard \& Poor's (2009), “India, Sovereign Credit Rating: Press Release”, February, p. 2. 
options and potential paths towards reform available to the Gol. ${ }^{61}$ It does not, however, prescribe a clear solution to the issue of pricing reform.

Naturally, pricing reform must not forsake the issue of equity and energy poverty in energy markets for a single-minded fixation with cost-minimisation. India's unofficial petroleum subsidies are specifically intended to ensure "the common man" is able to access and afford

Page | 54 basic energy needs. This principle should be upheld into the future. The process of product market reform therefore needs to be highly nuanced - reducing the cost of the current system of price regulation and enhancing price signals, while ensuring vulnerable Indian citizens are not excluded from energy markets. ${ }^{62}$

\section{Making markets work: the secondary benefits of reform}

Thus far, this chapter has discussed the need for product market reform largely in terms of the fiscal cost of the current system of unofficial subsidies. There are also other benefits to increasing market transparency and cost reflectivity, which should be noted. The first has to do with investment responses within India's downstream sector. Under current arrangements, India's public-sector downstream industry relies on a "managed" investment model. OMCs base investment decisions on a combination of public policy and expected demand, and investment capital is sourced from (or at very least indirectly and informally underwritten by) the Gol. This model of sectoral growth has been highly effective, but also highly costly, with the Gol bearing the burden of keeping OMCs in a condition to invest strongly. As in the conclusion of the preceding chapter, with the expected tightening of both budgetary conditions and international crude markets over time, the Gol will need to gradually move away from this expensive model of OMC investment.

Increasingly market-based pricing of refined product assists in this regard, in two key ways. Firstly, it allows OMCs to operate on a corporatised basis: without their vital revenue streams blocked, OMCs can profitably conduct operations that generate investment capital. Secondly, with revenue streams restored and investment capital generated, market-based pricing promotes (although of course, does not always ensure) adequate, timely and well-placed investment responses by providing clear price signals and transparent market drivers for investors. ${ }^{63}$ With more liberalised product markets, therefore, OMCs will be increasingly freed from reliance on the current government-funded mode of investment that ultimately burdens future generations. This does not mean that the Gol, OMCs' majority shareholder, need be completely excluded from a role in investment decisions, but implies instead that the resources and impetus for investments are derived from outside the organs and budgets of the Gol.

The second benefit of market-based reform not yet mentioned has to do with allocating energy consumption. India's subsidisation of petroleum products results in over-consumption of these products. Of course, when not facing the full cost of a product, consumers will use it in greater quantity than when they do face full costs. In the case of India's consumption of petroleum products, this has far-reaching economic and environmental implications. Overconsumption of petroleum products inevitably equates to Indian overconsumption of crude oil, $75 \%$ of which

\footnotetext{
${ }^{61}$ Current economic conditions make the perfect context for pricing reform as pent-up inflationary pressures, in India and elsewhere, waned significantly in 2009. As a result, the Gol can begin phased price rationalisation without concern that somewhat higher fuel costs might set off an inflationary spiral.

62 UNECE (2002), Draft Guidelines for Reforming Energy Subsidies, p. 3.

${ }^{63}$ Morgan, T. (2007), Energy Subsidies: How they Affect Investment and Greenhouse Gas Emissions, p. 15.
} 
India is required to import. With current crude prices remaining relatively high and broadly expected to rise, the income effect of India's huge crude import bill is significant. Cheap, subsidised petroleum products in India institutionalise heavy fuel use, and thoroughly undermine energy efficiency and conservation. This, at once, greatly increases India's crude costs, augments its dependence on foreign sources of oil and increases greenhouse gas emissions. Lastly, subsidised fuel prices entrench the use of fossil fuels and undermine substitution into cleaner fuels and energy-producing technologies. In establishing unfettered price signals for increasingly expensive petroleum fuels, the establishment of cost-reflective pricing therefore implies significant benefits for India and its economy. Better functioning price signals work to simultaneously increase energy efficiency, reduce greenhouse gas emissions and decrease total crude costs. ${ }^{64}$

The rationale for the Gol to begin market-based pricing reform is therefore threefold. Firstly, and most pressingly, the existing system of unofficial subsidies on petroleum products is unsustainably costly, especially given India's precarious budgetary position. Secondly, marketbased pricing will enhance the functioning and cashflows of OMCs, encouraging timely, wellplaced and independently-funded public-sector refinery investment, and reducing the reliance on taxpayer funding for this purpose. Lastly, market prices encourage conservation and substitution of petroleum products, reducing both crude import costs and greenhouse gas emissions. This is a comprehensive case. The difficult task, to which there are significant barriers, is therefore to design a programme of reform that establishes cost-reflective pricing at the centre of product markets, but that at the same time ensures petroleum products remain affordable to vulnerable consumers. This is important, of course, not only from the perspective of equity, but from one of political realism as well. ${ }^{65}$ The rest of this chapter is devoted to a discussion of some of the various ways to distil such a programme of reform.

\section{The possible roads to reform (or the road less travelled)}

\section{Price reform with targeted subsidies}

Apart from complete price liberalisation, the most efficient way for product markets to be reformed while maintaining a commitment to broad-based energy market access is through highly targeted subsidies to a small proportion of specifically-defined end users. These specific end users are issued with proof of entitlement to reduced-cost fuels. This same principle may be applied for firms using fuel inputs in industries of high strategic or social importance, for example, farmers of staple crops. The use of such a tool is powerful. As long as a sufficiently small proportion of consumers have access to subsidised fuel, price mechanisms in product markets will not be distorted. ${ }^{66}$ In such a situation, sensitive consumers are protected while the benefits of market prices (cost minimisation; least-cost, efficient investment responses; and fuel switching and conservation) are upheld.

Unfortunately, India's significant demographic and socio-economic complexities render such an approach problematic. Although exact figures vary, India has hundreds of millions of people living below the poverty line (BPL). Providing targeted subsidies to hundreds of millions of geographically dispersed individuals is clearly very difficult. If the task is not itself impossible,

${ }^{64}$ Von Moltke, A. et al. (2004), Energy Subsidies, pp. 45-49.

${ }^{65}$ Ibid., p. 12.

${ }^{66}$ Bashmakov, I. (2003), "Energy Subsidies and 'Right Prices'” in Energy Efficiency, Vol. 35. 
the regulatory costs of such a scheme are prohibitive. Further, given the endemic corruption India faces in low-level administration, it is highly unlikely that a precisely targeted system of subsidies would be effective in strictly confining the distribution of subsidised product to the targeted population group. As the Parikh Report states, such a system would "involve a complex monitoring and inspection structure more likely to promote Inspector Raj than to effectively Page $\mid 56$ reduce the subsidy" ${ }^{67}$ Currently, for example, the Gol operates a nominal system of quotas for the sale of subsidised kerosene, which are intended for sale to the poorest sections of India's population. In practice, it is too difficult for OMCs to properly monitor to whom these products are sold. A recent study showed that in ten of India's 28 states, more than $50 \%$ of subsidised product was sold to businesses and industry, rather than BPL cardholders. When sales to nonBPL individuals were included, the proportion diverted was as high as $85 \%$ in some states, and not less than $50 \%$ in others.

Given India's current social complexity, targeted subsidies cannot therefore provide the sole key to product market reform. They are however, an extremely important component of a larger reform programme, especially with regard to energy poverty-alleviating cooking fuels (as will be discussed below). The Gol recently introduced a pilot scheme in Hyderabad, Bangalore and Pune which aims to better target the distribution of subsidised LPG and kerosene to BPL Indians through the use of new-generation electronic Smart Cards. To the extent that this pilot is successful, this study supports the implementation of such a scheme. The barriers to effective country-wide implementation and proper governance of a very large targeted product subsidies system in India at the moment, however, are quite substantial.

\section{Taxation reform}

Since India's General Election in May 2009, several proposals for the reform of petroleum product pricing have been voiced. Prominent among these has been reform to the system of taxes levied on petroleum products. The Gol has been cutting excise taxes on petroleum products to ease under-recoveries for some time. The fresh proposals for tax reform call for further cuts to excise levels in combination with the implementation of a lower state-levied standardised sales tax rate. ${ }^{68}$ Negotiating a uniform sales tax amongst 28 Indian states (plus territories) is likely to be a long and painstaking process, although one that should be undertaken. More importantly, marginal reform to the system of petroleum product taxation is merely a "band-aid" solution which fails to solve the underlying issue of absent cost-reflectivity in product markets. Cutting petroleum taxes further should not even be considered a prudent short-term interim measure to stem under-recoveries. By cutting taxes the Gol undermines a crucial source of revenue, one that is extremely important given current budgetary conditions, and which may be spent in support of basic developmental programmes. Lastly, reducing taxes now will make it very difficult for future governments to raise taxation rates on petroleum products again, and hence deprives policy makers of a key demand-side management and environmental policy tool.

\footnotetext{
${ }^{67}$ Government of India (2010), Report of the Expert Group on a Viable and Sustainable System of Pricing Petroleum Products, February, p. 23.

${ }^{68}$ These proposals are described in Indian Oil \& Gas (2009), "Further Tax Cuts on Petrol Products?", Vol. 13, No. 12.
} 


\section{Price ceilings}

In May 2009, MPNG released a proposal for reform of diesel and petrol markets based on the establishment of a price ceiling under which product prices are allowed to fluctuate. Under this proposal, OMCs are free to set fuel prices every three months, based on a quarterly average of global crude prices. This will occur until crude prices reach USD $75 / \mathrm{bbl}$, at which point the Gol will intervene with price controls to protect consumers. This proposal is tacitly based on the notion that it is extreme product prices that cause the lion's share of damage to consumers' budgets and to economies. For all but the very poorest, market outcomes will not cause significant increases in individual hardship in most instances, especially in petrol and diesel markets. ${ }^{69}$ The role of subsidies should therefore be to insulate consumers from the extreme end of the petroleum product pricing range, while allowing markets to function at other times. ${ }^{70}$ The section below looks at the issues with MPNG's proposal and ways that it might be modified. Note, this is meant as a policy discussion rather than as offering a concrete solution to the issue of pricing reform.

\section{Establishing workable price ceilings in Indian product markets}

A key short-coming with MPNG's May 2009 proposal is that it fails to properly consider the realities of international crude markets. In May, concerns remained about the state of the global economy, and crude benchmark prices hovered around USD 55/bbl. Indeed, with economic recovery, crude prices were clearly destined to rise from this level. With the observed "bottoming" of the global economy, MPNG's price ceiling of USD 75/bbl has quickly become too conservative. Although benchmark prices only fairly recently reached USD 75/bbl since they touched a cyclical bottom of USD 32/bbl in early 2009, further economic recovery is likely to sustain still higher prices in the near term. For the purposes of reform, it is little use establishing a price ceiling which is consistently in effect. MPNG should examine the possibility of price ceilings for product markets, especially petrol and diesel markets, which are somewhat higher than USD 75/bbl. ${ }^{71}$ These ceilings need not be significantly higher. As the EIA argues in its November 2009 Short-term Energy Outlook, the world can still expect a significant period of relatively subdued crude prices as hopes of an economic recovery are balanced with persistently weak demand and historically high inventories. ${ }^{72}$ Price ceilings should, however, be high enough to create, to begin with at least, a "buffer" between current prices and the ceiling in which market prices can fluctuate.

The Gol should consider two different price ceilings that reflect two very different petroleum product markets - one for petrol and diesel, and one for LPG and kerosene. Petrol and diesel

\footnotetext{
${ }^{69}$ This is not to say that India's population will be happy with a removal of price controls. It is instead argued that, in most periods and for most individuals, market prices will not cause major hardship, especially in petrol and diesel markets.

${ }^{70}$ While MPNG's proposal sees "extreme" prices as those above USD 75/bbl, extreme prices here (taking into account credible medium-term crude price forecasts) are seen as those above approximately USD 110-120/bbl, similar to those experienced in the crude price-spike of mid- 2008.

${ }^{71}$ Suggesting exact price ceilings for different Indian product markets is beyond the scope of this paper.

${ }^{72}$ Energy Information Administration (2009), Short-Term Energy Outlook, November. Indeed, OPEC has made clear that they see USD 75/bbl as a "fair" target crude price for both producers and consumers.
} 
are primarily transport fuels, used above all by those with access to private vehicle transport. Diesel does have social uses in the transport of staple products, in public transport and for use in agricultural production. ${ }^{73}$ However, the majority of petrol and diesel in India is consumed by middle class Indians with access to private vehicles. The Gol should therefore consider relatively high price ceilings on petrol and diesel, allowing market prices to take affect in most instances, Page 58 while insulating consumers at times of very high prices (realistically defined). The social uses of diesel, especially for public transport and use in agriculture, may then be protected by direct subsidisation of these activities themselves, as suggested by the World Bank. ${ }^{74}$

Depending on exactly where the price ceiling for petrol and diesel is established, a relatively high ceiling (e.g., of USD 95-105/bbl) can be expected to increase petrol and diesel prices by around INR 9-10/litre (from current levels around INR 33/litre for diesel and INR 45/litre for petrol) at the higher reaches of the price scale, according to Platts. ${ }^{75}$ This jump in prices will over time increase fuel conservation and switching in India and work to promote increased retail competition in the downstream sector. At the same time, it should mostly impact middle-class and wealthy Indian citizens, greatly diminishing the overall welfare effect.

LPG and kerosene, on the other hand, are increasingly used as cooking fuels by India's poor population. ${ }^{76}$ The cheap substitute for these fuels is the hazardous practice of burning biomass in the home. The importance of accessible LPG and kerosene to the health and living standards of India's poor means that the price of LPG and kerosene is a highly sensitive developmental issue. Of course, these fuels are widely used in industry (and kerosene is an almost perfect substitute for jet fuel). However, prices cannot be liberalised in the same simple fashion as those of diesel and petrol. Neither, though, should healthy Indian industries benefit from costly subsidies aimed at poorer individuals. In order to balance these competing social and economic objectives, the Gol should, to begin with, assess the success of its ambitious Smart Card scheme for subsidised kerosene and LPG distribution. Clearly, India needs a means to effectively supply poor households with affordable cooking fuels before LPG and kerosene markets can begin to be properly deregulated. If the Smart Card scheme succeeds in more effectively targeting poor Indian households, MPNG should consider moving towards liberalised markets with price ceilings, although these ceilings might be quite low initially. If this pilot project is not successful, MPNG must look to concentrate its energies in thorough reform of the distribution of subsidised LPG and kerosene. Only then are the conditions created for deeper structural pricing reform in these key markets.

\section{A transition to liberalised markets}

Complexities in the consumption patterns and uses of different petroleum products therefore mean pricing reform across product markets requires a combination of both regulated marketbased reform, and targeted subsidies. In addition to this, as argued in Chapter 3 (and included in

\footnotetext{
${ }^{73}$ In pricing matters, diesel and petrol need to be treated together as they are almost perfect substitutes. More lax treatment of one will merely cause a shift in demand away from the other.

${ }^{74}$ Cropper, M. (2004), "Public Transport and Affordability in Mumbai, India", World Bank Working Papers.

${ }^{75}$ If retail prices were to be liberalised with global crude prices between USD 70-80/bbl, it is estimated that retail diesel and petrol prices would increase by around INR 4/litre. See Platts (2009), "India takes a fresh look at fuel pricing reforms - through antique glasses", 1 December.

${ }^{76}$ Kerosene is used much more widely than more expensive LPG for cooking by BPL Indians. However LPG is a cleaner-burning, healthier fuel, a fact that has motivated the Gol to attempt to foster the increasing use of LPG by BPL Indians.
} 
the $11^{\text {th }}$ Five-Year plan), India should work to establish national petroleum product markets, with uniform state-levied taxes on products. Although this will be a painstaking process, in the context of higher prices due to market liberalisation, national markets will reduce the natural upward pressure on prices resulting from "tax creep" - i.e., that resulting from the temptation of regional governments to periodically levy a variety of additional duties on the sale of petroleum products. Of course, transparent national petroleum markets have other significant additional benefits in providing investor certainty and enhancing the downstream business environment.

In petrol and diesel markets, price ceilings that are established in the process of market reform should be upwardly flexible, with the intention of phasing these out over a certain, sufficiently lengthy period that allows adjustment to liberalised markets. These timeframes, of course, should be clearly indicated by the Gol during the process of reform. Adjustments in price ceilings should take place on the basis of clear criteria, relating to consumer price index changes, broad changes in incomes and consumption patterns, the effectiveness of parallel subsidies (for example, those for public transport), changing fuel intensity and the extent of fuel switching. ${ }^{77}$ Further, both revisions to price ceilings, and the eventual phasing out of price controls, should be monitored and undertaken by an independent body - e.g., the PNGRB - in order to avoid the politicisation of decisions. As has been mentioned, comprehensive liberalisation of LPG and kerosene markets first requires the establishment of an effective system of distribution for subsidised cooking fuels to BPL Indian households (effectively a wellfunctioning parallel market). To the extent that this system is successfully established and perfected over time, LPG and kerosene markets may take a similar structure to that proposed for petrol and diesel markets, including the gradual upward revision and phasing out of price ceilings, as consumers and industry adapt to more liberalised markets.

\section{Epilogue}

Petrol and diesel markets are therefore ripe for the Gol to begin pricing reform. This need not occur rapidly. Before semi-permanent price-ceilings (of the kind explored above) are established in petrol and diesel markets, the Gol ought to slowly increase current maximum prices for products so as to ease the transition to higher and somewhat more permanent price ceilings. Increasingly liberalised petroleum and diesel markets would represent a significant step in reducing the massive cost of product subsidies for the Gol. In FY 2008-09, under-recoveries on the sale of petrol and diesel in India exceeded USD 15 billion, close to $60 \%$ of the total underrecovery burden. Of course, during a transition to market prices, under-recoveries on the sale of diesel and petrol would not disappear. In fact, secondary subsidies protecting the social uses of diesel (e.g., in public transport) would likely need to be put in place, representing an additional fiscal cost. Nevertheless, the Gol should anticipate huge savings in the form of foregone debt issuance as a result of phased pricing reform in petrol and diesel markets, especially if crude prices rise in the short-to-medium-term.

The likely investment effect occurring within India's downstream petroleum sector in the longterm as a result of pricing reform has been explored above. The Gol, should not, however, expect to see a rapid expansion of private-sector refining investment in response to deregulated

\footnotetext{
${ }^{77}$ MPNG should look to task PPAC with collection of data pertaining to these criteria (or whichever criteria they devise) so that transparent and fully-informed decisions may be made by bodies assessing the level of price ceilings.
} 
prices in the short-term. Although IOCs and other private-sector refiner-retailers are likely to be strongly drawn by the opening of Indian product markets (and especially product retail markets), refinery capacity investment in the Asia-Pacific region in general will be muted by close-to-unprecedented regional excess refining capacity in the period to 2012-13.

This study has argued that refinery investment in India should be increasingly sought from the private-sector in the long-term. The natural unpredictability and "lumpiness" of private-sector refining investment, however, combined with the traditional boom-bust pattern of global and regional refining investment provides a justification for retaining a degree of government involvement in Indian downstream sector investment, where high-speed demand growth and dynamic commercial opportunities require decisive and early investment responses to avoid supply shortfalls. Especially in the period to 2012-13, the Gol should look to maintain its tacit control over OMCs' strategic expenditures, even as OMCs' reliance on government revenue for working capital gradually diminishes with more liberal pricing. In this way, the Gol can ensure that the incremental investment necessary to maintain downstream sector dynamism and growth is realised. Indeed, the Gol can perhaps divert a proportion of the plentiful revenue saved by market reform to provide assistance to OMCs in making these important infrastructure and capacity additions.

Realistically, the Gol is unlikely to take major steps towards product market liberalisation in the short-term, despite the ambitious reform proposed by the Parikh Report. Part of this policy stasis stems from upward-trending crude prices in late-2009, which provide policy makers with a hostile environment for reform. It is very difficult to embark on a process of groundbreaking market deregulation when policy makers fear that, in doing so, they may expose economicallycritical and politically-sensitive product markets to a destabilising period of increasing global crude prices.

However, with increases in crude benchmark prices very likely in 2010 as global economic activity recovers, the consequence of maintaining the current system of unofficial petroleum product subsidies will again be rapidly mounting under-recoveries, and a re-emergence of fiscal imbalance in India as the Gol is forced into debt issuance to support OMCs. According to the IEA's 2009 Medium-Term Oil Market Report, international crude markets are likely to tighten considerably in the medium-term, especially in comparison to conditions in the aftermath of the global economic slowdown of 2008-09. ${ }^{78}$ Given the fiscal situation that India currently faces, maintaining current product pricing arrangement in the medium-term under tight oil market conditions and in an environment of high crude prices is entirely unrealistic. In the following years, the Gol will thus need to begin thorough product market reform in order to institutionalise more sustainable, less costly pricing practices. It should look to initiate this process as soon as possible, to both take advantage of relatively moderate crude prices currently, and to allow Indian consumers an ample period of transition to liberalised markets.

\footnotetext{
${ }^{78}$ IEA (2009), Medium-Term Oil Market Report, July, pp. 2-3.
} 


\section{Bibliography}

Bashmakov, I. (2003), “Energy Subsidies and 'Right Prices'”, in Energy Efficiency, Vol. 35.

Business Monitor (2009), India Oil and Gas Report, Q3 2009, June.

CRISIL (2010), Hindustan Petroleum Corporation Limited: Debt Instruments and Bank Facilities, January.

Cropper, M. (2004), "Public Transport and Affordability in Mumbai, India", World Bank Working Papers.

FACTS Global Energy (2009), Asia Pacific Refinery Configuration and Construction: Oil Databook II, Volume 1, April.

FACTS Global Energy (2009), Asia-Pacific Oil Product Balances, Oil Databook III, Volume 1, April.

Government of India, The Parikh Committee (2010), Report of the Expert Group on a Viable and Sustainable System of Pricing Petroleum Products, February.

Government of India, Ministry of Finance (2009), Union Budget, Key Excerpts, July.

Government of India, Petroleum Planning and Analysis Cell (2009, 2010), Oil Prices and Taxes, available at www.ppac.org.in.

Government of India, Planning Commission (2007), "Petroleum and Natural Gas Chapter", Eleventh Five-Year Plan.

Indian Oil \& Gas (2009), "Further Tax Cuts on Petrol Products?”, Vol. 13, No.12.

International Energy Agency (2008), World Energy Outlook, November.

International Energy Agency (2009), Medium-Term Oil Market Report, June.

International Energy Agency (2010), Oil Market Report, February, p. 53.

Morgan, T. (2007), Energy Subsidies: Their Magnitude, How they Affect Energy Investment and Greenhouse Gas Emissions, and Prospects for Reform, June.

Organisation of Petroleum Exporting Countries (OPEC) (2009), World Oil Outlook.

Platts (2009), "India Takes a Fresh Look at Fuel Pricing Reforms - Through Antique Glasses", 1 December.

Standard \& Poor's (2009), India Sovereign Credit Rating: Press Release, February.

The Hindu (2009), "India Clocks 6.6 Percent Growth in 2008-2009", 30 May.

United Nations Economic Commission for Europe (UNECE) (2002), Reforming Energy Pricing and Subsidies: Part 2 Guidelines for Reforming Energy Subsidies, Geneva.

United States Government, Energy Information Administration (2009), India Country Report, March.

United States Government, Energy Information Administration (2009), International Energy Outlook, May.

United States Government, Energy Information Administration (2009), Short-term Energy Outlook, November. 
Von Moltke, A., C. McKee and T. Morgan (2004), Energy Subsidies: Lessons learned in Assessing their Impact and Designing Policy Reforms, United Nations Environment Programme.

Wall Street Journal (2006), "Giant Oil Refinery in India Shows Forces Roiling Industry", 29 August.

Page | 62 World Bank (2008), World Development Report 2009, November. 


\section{Abbreviations}

\begin{tabular}{|l|l|}
\hline Term & Description \\
\hline APM & Administrative Pricing Mechanism \\
\hline Bbl/d & Barrels per day \\
\hline BPCL & Bharat Petroleum Corporation Limited \\
\hline BPL & Below the Poverty Line \\
\hline CPCL & Chennai Petroleum Corporation Limited \\
\hline EOUs & Export-Oriented Units \\
\hline FIPB & Foreign Investment Promotion Board \\
\hline FY & Fiscal Year \\
\hline Gol & Government of India \\
\hline HPCL & Hindustan Petroleum Corporation Limited \\
\hline IEP & Integrated Energy Policy \\
\hline IOCL & Indian Oil Corporation Limited \\
\hline IOCs & International Oil Companies \\
\hline LPG & Liquefied petroleum gas \\
\hline Mb/d & Million barrels per day \\
\hline MPNG & Ministry of Petroleum and Natural Gas \\
\hline MPRL & Mangalore Refinery and Petrochemicals Corporation Limited \\
\hline MTOMR & Medium-Term Oil Market Report \\
\hline OMCs & Oil Marketing Companies \\
\hline PNGRB & Petroleum and Natural Gas Regulatory Board \\
\hline PPAC & Petroleum Planning and Analysis Cell \\
\hline PSU & Public-Sector Undertaking \\
\hline RBI & Reserve Bank of India \\
\hline RIL & Reliance Industry Limited \\
\hline SEZs & Special Economic Zones \\
\hline SLR & Statutory Liquidity Ratio \\
\hline S\&P & Standard \& Poor's \\
\hline
\end{tabular}





\section{iea}

\section{International Energy Agency}
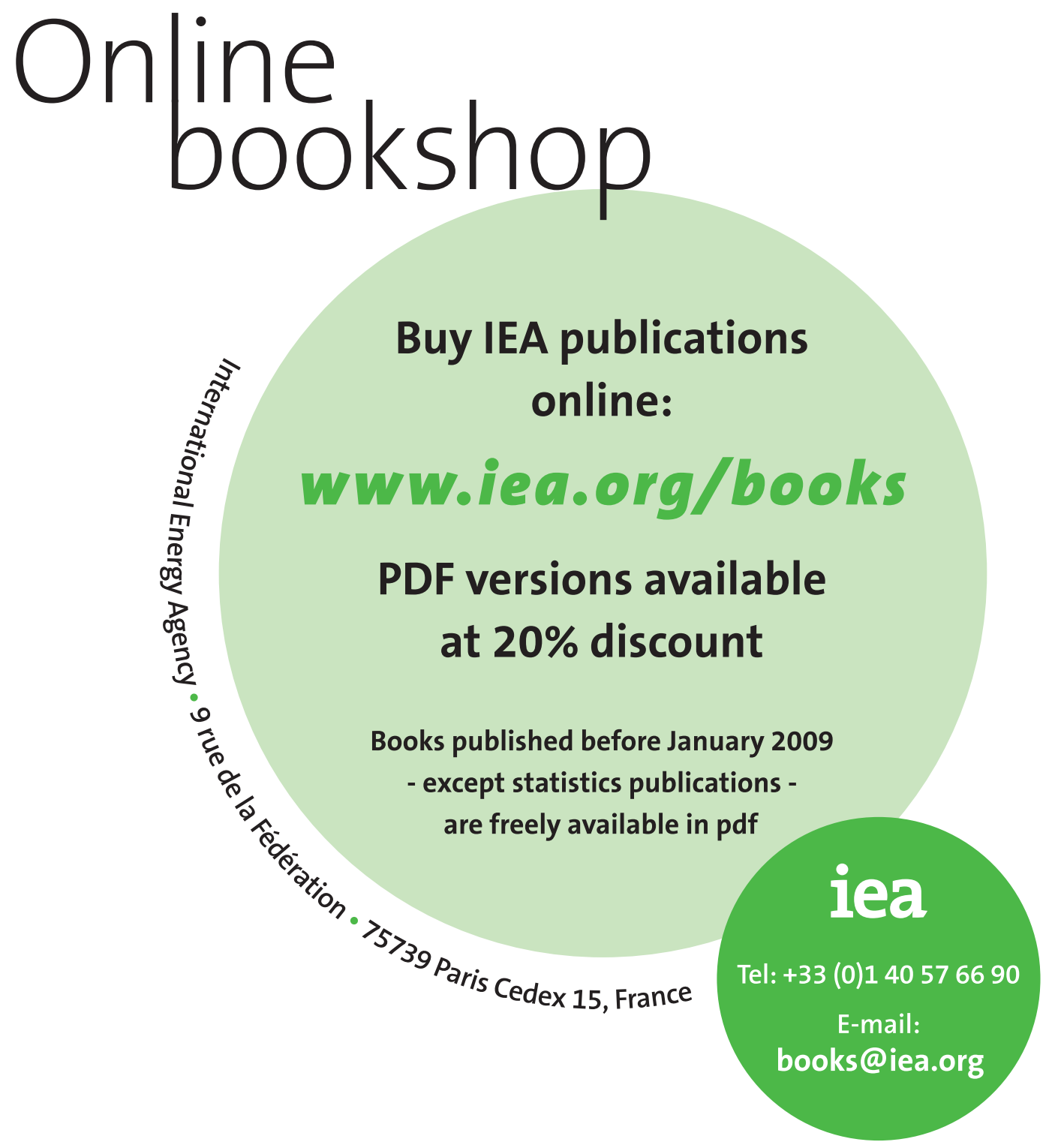


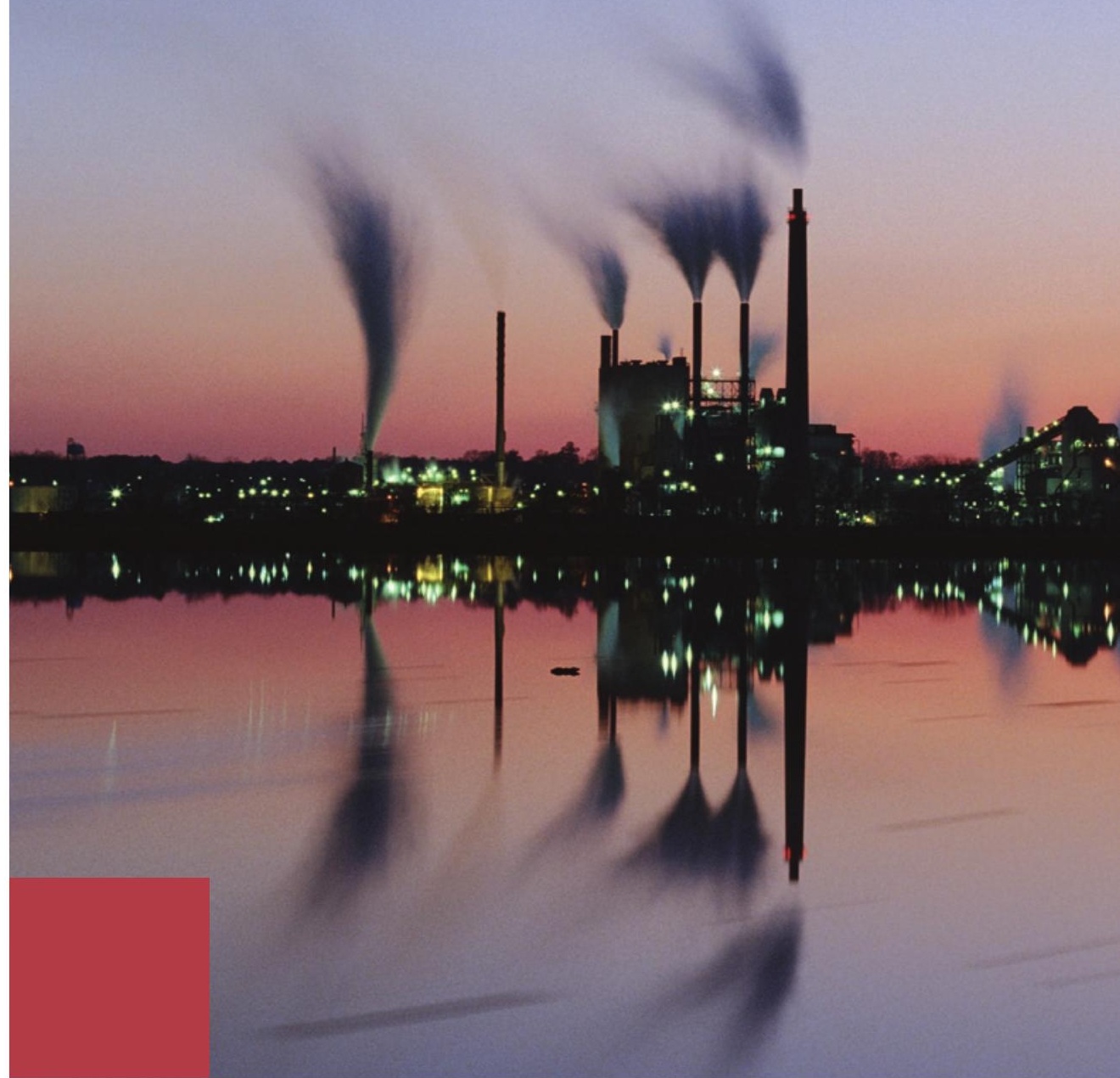

International Energy Agency

9 RUE de la Fédération 75739 Paris Cedex 15

www.iea.org 